\title{
Zur Einführung: Die Aufklärung in Europa und die Vorgeschichte der Amerikas oder: Warum das europäische Siècle des Lumières nicht ohne Amerika verstanden werden kann
}

Im Jahre 1971, kurz nach den turbulenten Ereignissen des Mai '68 in Paris, eröffnete der renommierte französische Aufklärungsforscher Pierre Chaunu seine Studie zur Civilisation de l'Europe des Lumières - zur Zivilisation im Europa der Aufklärung - mit den Worten: „Entre 1680 et 1770, voire 1780, une réalité s’impose, dense, difficile à cerner, certes, pourtant irréfutable: l'Europe des Lumières.“1 Zwischen 1680 und 1770, vielleicht sogar 1780, sei eine neue Realität entstanden, welche nur schwer zu fassen, aber auf Grund ihrer Dichte auch nicht zu leugnen sei: das Europa der Aufklärung.

Diese Bemerkung ist heute in der Aufklärungsforschung sicherlich unstrittig. ${ }^{2}$ Doch ein halbes Jahrhundert später ließe sich mit guten Gründen die folgende kleine Frage anschließen: Nur in Europa? Unsere komparatistisch angelegte Vorlesung will versuchen, nach der verlorenen, aus dem Bewusstsein zumindest der europäischen Forschung ausgeblendeten Einheit der Aufklärung und nach den transatlantisch verflochtenen Geschichten des 18. Jahrhunderts im Horizont der Vielgestaltigkeit aufklärerischer Diskurse in zwei Welten, in Europa und den Amerikas, zu fragen. Gab es eine Aufklärung oder gab es deren viele? Was zeichnet die Texte der „Lumières“ in Frankreich und Deutschland, in Spanien und Neuspanien sowie in anderen Areas und Regionen Europas und Amerikas aus? Welche Funktionen besitzen aufklärerische Diskurse innerhalb der jeweiligen nationalen (und protonationalen) Gesellschaften und Nationalliteraturen sowie innerhalb einer umfassenden, nicht auf Europa beschränkten „République des Lettres“? Welche Rolle spielten die Reisenden und Reiseschriftsteller, die „philosophes voyageurs“, innerhalb einer Aufklärung zwischen zwei Welten? Was bestimmte die Rezeption der deutschen Aufklärung in Neuspanien beziehungsweise in Mexiko, in welcher Beziehung stehen die Texte Voltaires oder die Encyclopédie, die Werke eines Rousseau oder Kant zu den Schriften von Cadalso, Mutis oder Clavijero?

Mit einem deutlichen Schwerpunkt innerhalb der Romania, mit einem romanistisch geprägten Verständnis des Begriffs der Amerikas und ohne jeden

1 Chaunu, Pierre: La Civilisation de l'Europe des Lumières. Paris: Flammarion 1982, S. $7 \mathrm{f}$.

2 Vgl. zum Begriff der Aufklärung Krauss, Werner: Aufklärung. Bd. III. Hg. M. Fontius. Berlin New York: de Gruyter 1996.

Ә Open Access. ( 2021 Ottmar Ette, publiziert von De Gruyter. (c) BY-NC-ND Dieses Werk ist lizenziert unter einer Creative Commons Namensnennung - Nicht-kommerziell - Keine Bearbeitung 4.0 International Lizenz. https://doi.org/10.1515/9783110703467-001 
Anspruch auf Vollständigkeit will unsere Vorlesung ein Verständnis dafür wecken, auf welche Weise im „Siècle des Lumières“, im „Siglo de las Luces“, inter- und transkulturelle Kontakte und Beziehungen im Bereich von Literatur, Philosophie und Kultur vonstattengingen. Wir wollen verstehen, wie die literarischen Räume der Aufklärung europäisch, amerikanisch und transatlantisch in Bewegung gesetzt und gehalten wurden und wie der reiche Formenschatz der Reiseliteratur als ein entscheidendes Transportmedium für dieses transatlantische „Enlightenment“ aufgefasst werden könnte. Ziel der mit diesen einführenden Worten eröffneten Vorlesung ist es, aus vergleichender Sicht nationalliterarisch eingefärbte monolinguale und monokulturelle Bilder der Aufklärung wie der sich anbahnenden Moderne zu hinterfragen und dabei bewusst kein breit ausgemaltes Panorama der Lumières, sondern eine programmatisch transareale Ausweitung ${ }^{3}$ unseres Blickes auf das 18. Jahrhundert zu entfalten.

Ich möchte dabei als bevorzugten Ort der Transmission vieler Übersetzungsvorgänge zwischen Alter und Neuer Welt eine Area wählen, welche während der ersten wie der zweiten Phase beschleunigter Globalisierung ${ }^{4}$ eine enorm wichtige Rolle spielte und als Zone verdichtetster Globalisierung bezeichnet werden kann. Es ist notwendig, bei unserer Annäherung an ein transatlantisches 18. Jahrhundert eine gewisse historische Tiefenschärfe einzubauen, um die historisch akkumulierte Asymmetrie der Beziehungen zwischen beiden Welten besser einordnen und verstehen zu können. ${ }^{5}$ So möchte ich Sie gleich mitten ins Geschehen zu Beginn der ersten Phase beschleunigter Globalisierung führen, in welcher sich einer ihrer Protagonisten mit der literarischen Tradition beschäftigte, welche im Abendland über weit entfernte Welten verfügbar war. Wir schauen einer der großen Entdeckergestalten bei der aufmerksamen Lektüre über die Schulter:

Gehen wir nun zur Beschreibung der Regionen Indiens über; beginnen wir mit der Insel Ciampagu, welches eine Insel im Ostsen auf hoher See ist, von der Küste von Mangi tausendvierhundert Meilen entfernt. Sie ist extrem groß und ihre Einwohner, weiß und schön gestaltet, sind Götzendiener und haben einen König, sind aber gegenüber niemand anderem tributpflichtig. Dort gibt es Gold in größtem Überflusse, doch der Monarch erlaubt es nicht leicht, dass welches von der Insel ausgeführt werde, so dass nur wenige Händler dorthin gehen, und selten laufen Schiffe aus anderen Regionen in die dortigen Häfen ein. Der König der Insel besitzt einen großen Palast, der Dächer aus sehr feinem

3 Vgl. hierzu Ette, Ottmar: TransArea. Eine literarische Globalisierungsgeschichte. Berlin - Boston: Walter de Gruyter 2012.

$4 \mathrm{Zu}$ den insgesamt vier Phasen beschleunigter Globalisierung vgl. ebda., S. 1-49.

5 Vgl. hierzu Ette, Ottmar: Asymmetrie der Beziehungen. Zehn Thesen zum Dialog der Literaturen Lateinamerikas und Europas. In: Scharlau, Birgit (Hg.): Lateinamerika denken. Kulturtheoretische Grenzgänge zwischen Moderne und Postmoderne. Tübingen: Gunter Narr Verlag 1994, S. 297-326. 
Gold hat, so wie bei uns die Kirchen mit Blei überdacht sind. Die Fenster dieses Palastes sind allesamt mit Gold ausgekleidet, und der Boden der Säle und vieler Gemächer ist von Bohlen aus Gold bedeckt, die zwei Finger dick sind. Dort gibt es Perlen in extremem Überflusse, welche rund und dick und von roter Farbe sind, so dass sie an Preis und an Wert die weißen Perlen noch übertreffen. Auch gibt es viele Edelsteine, weshalb die Insel Ciampagu wunderbar reich ist. ${ }^{6}$

Ich zitiere hier aus einer Ausgabe, die kein Geringerer als Christoph Kolumbus alias Cristóbal Colón vor Augen hatte und aus der er gerne zitierte. Und Kolumbus las sehr aufmerksam. Denn mit diesen Worten beginnt im zweiten Kapitel des dritten Buches von Marco Polos ursprünglich in den Jahren 1298 und 1299 abgefassten Il Milione die berühmte Beschreibung der Insel Ciampagu oder Cipango, in der wir die erste Schilderung des japanischen Insel-Archipels erkennen dürfen.

Kolumbus las und notierte, unterstrich und kommentierte. Es ist unmöglich, die vom 1254 in Venedig geborenen und dort im Jahr 1324 verstorbenen Marco Polo angefertigte ,Urschrift‘ des Reiseberichts, den der Venezianer in genuesischer Gefangenschaft seinem Freund Rustichello da Pisa diktierte und die dieser in altfranzösischer Sprache aufzeichnete, heute noch ausfindig zu machen. Genauso würde man auch vergeblich versuchen, in der hier nach einer spanischen Fassung zitierten Passage den ,authentischen` Beginn des Erscheinens der karibischen Inselwelt in der europäischen Literatur zu bestimmen. $\mathrm{Zu}$ vielfältig sind die Ursprünge und Herkünfte jener Projektionen, die seit der Antike nach Westen auf eine ,Neue Welt‘ übertragen wurden, bevor sie auf der ersten Reise des Kolumbus unter der Feder des genuesischen Seefahrers im berühmten Bordtagebuch, dem Diario de a bordo der Jahre 1492 und 1493, konkretere Gestalt anzunehmen begannen. Es kann keinen Zweifel daran geben, dass die Erfindungen Amerikas vieles mit den Bildern aus Fernost, aus dem fernen Asien, zu tun haben. Wer wollte in diesem von Europa aus gedachten Entwurf einer golden schimmernden Welt Asiens den Beginn einer Darstellung der karibischen Inselwelt erblicken?

Und doch begann sich spätestens mit Marco Polos Il Milione jenes koloniale Kaleidoskop zu drehen, in dessen Bewegungen sich Erfundenes und Gefundenes, ,Fakten“ und ,Fiktionen', Inselwelten Asiens und Inselwelten der Amerikas auf immer wieder neue Weise miteinander kombinierten. Ich werde mich diesem Problemkreis der Findung und Erfindung Amerikas in einer eigenen Vorlesung zu-

\footnotetext{
6 Polo, Marco / Kolumbus, Christoph / Santaella, Rodrigo de / Gil, Juan: El libro de Marco Polo anotado por Cristóbal Colón. El libro de Marco Polo versión de Rodrigo de Santaella. Edición, introducción y notas de Juan Gil. Madrid: Alianza Editorial 1987, S. 132. Alle Übersetzungen ins Deutsche stammen in diesem Band, wo nicht anders angegeben, vom Verfasser. Die Zitate in der Originalsprache finden die Leserin und der Leser im Anhang des Bandes (O.E.).
} 
wenden, in welcher das Erfinden sich vom konkreten Auffinden epistemologisch kaum trennen lässt. ${ }^{7}$ Hatte nicht schon Alexander von Humboldt auf eindrucksvolle Weise in seinem zwischen April 1834 und August 1838 in Paris und in französischer Sprache erschienenen Examen critique de l'histoire de la géographie du Nouveau Continent et des progrès de l'astronomie nautique aux quinzième et seizième siècles ${ }^{8}$ gezeigt, wie oberflächlich es wäre, in der langen und widersprüchlichen Geschichte der europäischen ,Entdeckung‘ der amerikanischen Hemisphäre simpel zwischen Fakten und Fiktionen zu unterscheiden?

Denn längst hatte eine genaue Analyse aller im 19. Jahrhundert vorliegenden Dokumente ergeben, in welchem Maße die Fiktionen Fakten geschaffen hatten, die ihrerseits neue und höchst wirksame Kreisläufe von Fiktionalität und Faktizität in Gang zu setzen vermochten. Diese verschiedenen Kreisläufe und Konfigurationen des erfundenen Gefundenen wie des gefundenen Erfundenen setzten sich auf immer wieder neue Weise kaleidoskopartig miteinander in Beziehung - und man könnte die Behauptung wagen, dass auch wir im 21. Jahrhundert noch immer von diesen Imagologien und Bilder-Welten tiefgründig beeinflusst sind. Wie könnten wir heute behaupten, dass diese Verschränkungen von Faktischem und Fiktionalem, ja von fiktional erzeugtem Faktischen viel von ihrer Wirkmächtigkeit eingebüßt hätten? Lange vor dem Erscheinen von Humboldts Examen critique stand das 18. Jahrhundert noch vollständig im Bann dieser auf langen, eng miteinander verflochtenen Traditionen basierenden Welt-Bilder, in welchen gerade Asien den Bilderspeicher stellte, den man aus Europa nur allzu gerne auf Amerika richtete.

So ließe sich mit guten Gründen sagen: Die erste Reise eines Europäers durch die Karibik und somit durch die Tropen Amerikas war eine Reise des Lesens. Und Le livre de Marco Polo citoyen de Venise, dit Milione, où l'on conte les merveilles du monde hat daran einen wohl kaum zu überschätzenden Anteil. Asien ist tief in die europäischen Bildwelten Amerikas hineingesenkt. Christoph Kolumbus mag zwar noch Jahre nach seiner ersten Fahrt ,seinen' Marco Polo nur aus vielen indirekten

7 Vgl. den sechsten Band der Reihe „Aula“ in Ette, Ottmar: Erfunden Gefunden (2022).

8 Vgl. hierzu auch die deutschsprachige Edition einschließlich ihrer in Humboldts Atlas sichtbaren und unsichtbaren Kartenwerke in Humboldt, Alexander von: Kritische Untersuchung zur historischen Entwicklung der geographischen Kenntnisse von der Neuen Welt und den Fortschritten der nautischen Astronomie im 15. und 16. Jahrhundert. Mit dem geographischen und physischen Atlas der Äquinoktial-Gegenden des Neuen Kontinents Alexander von Humboldts sowie dem Unsichtbaren Atlas der von ihm untersuchten Kartenwerke. Mit einem vollständigen Namen- und Sachregister. Nach der Übersetzung aus dem Französischen von Julius Ludwig Ideler ediert und mit einem Nachwort versehen von Ottmar Ette. 2 Bde. Frankfurt am Main Leipzig: Insel Verlag 2009. 


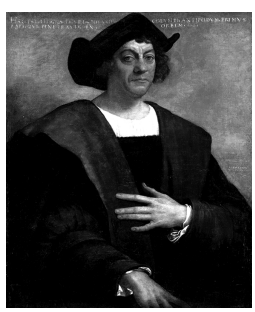

Abb. 1: Sebastiano del Piombo: Porträt eines Mannes, möglicherweise Christoph Kolumbus (ca. 1451-1506), 1519.

Quellen geschöpft und diese zunächst ohne die Kenntnis eines unmittelbaren Quellentextes auf die antillanische Inselwelt projiziert haben. ${ }^{9}$ Doch tragen die Anmerkungen des Admirals in der ihm spätestens seit 1497 zur Verfügung stehenden und auf uns gekommenen Abschrift doch mit aller Deutlichkeit die Handschrift einer Lektüre, die nach direkter, pragmatischer Übertragung und folglich nach konkretem Handeln drängt. So lauten die direkten Anmerkungen des Genuesen zur eingangs zitierten Passage des Millione schlicht: „oro en grandísima abundancia“ - „perlas rojas“10 - Gold in allergrößtem Überfluss und rote Perlen! Das von Colón betätigte koloniale Kaleidoskop projizierte seine glänzenden Bilder in Hülle und Fülle: traumhafte Tropen, fürwahr!

Gleichsam unter der Insel Kuba erscheint eine andere Insel namens Cipango, die den nie erreichten Traum des Kolumbus, nach Indien und den gesamten ,fernen' Osten auf dem Westweg zu gelangen, in eine schillernde, vielschichtige Realität verwandelte. Ebenso zeichnet sich schon bei Marco Polo im achten Kapitel des dritten Buches die Überzeugung ab, dass wir es nicht mit einer Insel, sondern einer vielgestaltigen, dem asiatischen Kontinent vorgelagerten Inselwelt zu tun haben:

Das Meer, in welchem sich die Insel von Ciampagu befindet, ist ein Ozean und heißt Meer von Cim, das heißt „Meer von Mangi“, da die Provinz von Mangi sich an seiner Küste befindet. In dem Meer, in welchem sich Ciampagu befindet, gibt es andere sehr zahlreiche Inseln, die sorgsam von den Seeleuten und Steuermännern jener Region gezählt wurden, und so hat sich gefunden, dass es siebentausend und 378 sind, von denen der größte Teil von Menschen bevölkert ist. Auf den genannten Inseln sind Bäume und Büsche voll Spezereien, denn dort wächst kein Strauch, der nicht sehr aromatisch und nützlich wäre. Dort gibt es unendliche Spezereien, es gibt Pfeffer, so grellweiß wie der Schnee; es gibt auch den höchsten Überfluss an schwarzem Pfeffer. Bei alledem schiffen nur selten Händler von andernorts hierher, da sie ein ganzes Jahr auf dem Meer verbringen müssen, inso-

9 Vgl. hierzu Gil, Juan: Libros, descubridores y sabios en la Sevilla del Quinientos. In: El libro de Marco Polo anotado por Cristóbal Colón, S. vi f.

10 Ebda., S. 132. 
fern sie im Winter losfahren und im Sommer zurückkehren. Denn nur zwei Winde herrschen in jenem Meere, der eine im Winter und der andere im Sommer. ${ }^{11}$

Ohne an dieser Stelle detailliert auf die Präsenz Marco Polos in Cristóbal Colóns Bordtagebuch eingehen zu wollen, sei doch betont, dass der genuesische Seefahrer auch am Rande dieser Passage nicht nur die erwähnten Reichtümer vermerkt sowie die jahreszeitlich genutzten Schifffahrtswege notiert. Zudem blendet er pragmatisch in die von ihm durchfahrene Karibik jene asiatische Inselwelt ein, die sich in seinen Augen in und unter der amerikanischen Inselwelt abzeichnet. Mit Christoph Kolumbus kommt Asien nach Amerika - und dies wird nicht allein an der Bezeichnung „Indios“ für die Ureinwohner Amerikas deutlich.

Doch bleiben wir bei den von Marco Polo beschriebenen Inselwelten, die komplexe Archipele konfigurieren und mit denen der Weltreisende und venezianische Geschäftsmann die Möglichkeit der Etablierung profitabler Handelsbeziehungen nahelegt! Der Genuese überträgt diese Visionen des Venezianers in seine Kartographie, von der er zu keinem Zeitpunkt seines Lebens annahm, dass sie keine asiatische sein könnte. Bekanntlich war sich Christoph Kolumbus bis zu seinem Lebensende nicht der Tatsache bewusst, nicht nach Asien gelangt, sondern einen anderen Kontinent, eine für die Europäer ,Neue Welt' entdeckt zu haben. So verkörpert sich die Inselwelt Asiens mitsamt ihren altweltlichen Nymphen und Meerjungfrauen in jener archipelischen Welt der Karibik, ohne deren unvermitteltes - wenn auch fälschlich erwartetes - Auftauchen Kolumbus mit seinen Schiffen im Meer verschwunden wäre, hätte er mit seinen Karavellen doch aufgrund der immensen Entfernung die Küsten und Inseln Asiens niemals mehr erreicht. Es war mithin die Fiktion einer Inselwelt, die Kolumbus zunächst anlockte und später als tatsächlich ,aufgefundene، das Leben rettete. Folglich ließ er sich bis zu dessen Ende niemals mehr von seinem festen Glauben abbringen, mit jenen Inseln und Teilinseln, die wir heute Kuba und Jamaica, Haiti, Santo Domingo oder Martinique nennen, das Asien des Marco Polo erreicht zu haben. Welchem Kontinent also gehört die Karibik?

Bedeutsam scheint mir an der mit dieser Überlagerungsvorstellung aufgeworfenen Problematik weniger die Tatsache, dass Kolumbus von seinen Überzeugungen selbst zu einem Zeitpunkt nicht ablassen wollte, zu dem sich längst die These einer ,Neuen Welt` zu verbreiten begann. Vielmehr ist die Erkenntnis wichtig, dass sich im erstmals global, also die gesamte Erdkugel umspannend gedachten Projekt des Genuesen, die - wie wir heute wissen - atlantischen und pazifischen Inselwelten untrennbar transarchipelisch überlagerten. So sind die

11 Ebda., S. 136. 


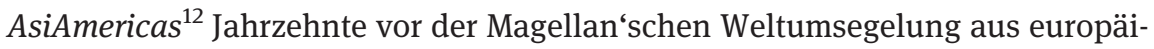
scher Sicht ein Faktum, das spätestens seit Kolumbus, dem ,Entdecker‘ und zugleich Leugner einer ,Neuen Welt‘, von Fiktionen unterschiedlicher Provenienz, unterschiedlicher ,Ursprünge‘, geschaffen wurde.

In einer einflussreichen und für das 18. Jahrhundert charakteristischen Passage hat Voltaire sich mit der berühmten Anekdote beschäftigt, wie Kolumbus seine Neider und kartographischen Gegner von der Kugelgestalt der Erde überzeugen wollte. Dabei fand er für Colombo - den er bei seinem italienischen Namen nennt - die schöne Formulierung, jener habe die Werke der Schöpfung mit einem Male verdoppelt. Dies ließe sich aus unserer Perspektive sowohl für die ,Entdeckung، Amerikas als auch für die Verdoppelung Asiens in Amerika sagen:

Die Antwort des Colombo auf diese Neider ist berühmt. Sie sagten, dass nichts einfacher wäre als seine Entdeckungen. Er schlug ihnen vor, ein Ei aufrecht zu halten; und da niemand es vermochte, zerbrach er das Ei an einem Ende und stellte es aufrecht hin. „Dies wäre doch sehr einfach, sagten die Anwesenden. - Warum habt Ihr es dann nicht angeraten?“, antwortete Colombo. Diese Geschichte wird von dem großen Künstler Brunelleschi berichtet, der die Architektur in Florenz lange vor Colombos Existenz reformierte. Die meisten Bonmots sind Nachgesagtes.

Die Asche des Colombo interessiert sich nicht mehr für den Ruhm, den er während seines Lebens dafür genoss, dass er für uns die Werke der Schöpfung verdoppelte; aber die Menschen lieben es, den Toten Gerechtigkeit widerfahren zu lassen, sei es, dass sie sich in der eitlen Hoffnung wiegen, sie den Lebenden zukommen zu lassen, sei es, dass sie natürlich die Wahrheit lieben. ${ }^{13}$

Für Voltaire war Christoph Kolumbus unstrittig jener große Mann, der durch seine Taten die Werke der Schöpfung verdoppelt und „pour nous“, also für die Europäer, den Zugang zur gesamten Erdkugel hergestellt hatte. Dies habe die historische Größe des genuesischen Seefahrers ausgemacht, auch wenn dieser zu Lebzeiten die Bedeutung seiner Entdeckungen nicht gänzlich überblickt und verstanden habe. Es erscheint vor diesem Hintergrund als überaus bedeutungsvoll, dass der Admiral im Dienste der Katholischen Könige im Jahre 1498 in das untere linke Feld seines viergeteilten Wappens (Abb. 2) jene Welt von Inseln aufnahm,

12 Vgl. hierzu Ette, Ottmar / Mackenbach, Werner / Nitschack, Horst (Hg.): TransPacífico. Conexiones y convivencias en AsiAméricas. Un simposio transareal. Berlin: Verlag Walter Frey edition tranvía 2013.

13 Voltaire: De Colombo, et de l'Amérique. In (ders.): Euvres complètes de Voltaire. Texte établi par Louis Moland. Bd. 12: Essai sur les mœurs (2). Paris: Garnier 1883, S. 379. Zur Präsenz von Kolumbus in der französischen Literatur. vgl. König, Gerd Johann: Kolumbus-Epik. Die Inszenierungen eines Helden in französischen und neulateinischen Texten ab 1750. Berlin - Boston: Walter de Gruyter 2021. 
deren Auftauchen aus dem Meer ihm buchstäblich das Leben gerettet hatte - und deren Auffindung ihn für alle Zukunft berühmt machen sollte. ${ }^{14}$

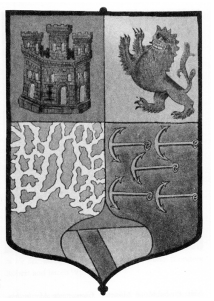

Abb. 2: Wappen des Christoph Kolumbus, 1498.

Diese heraldische beziehungsweise graphische Darstellung der amerikanischen Inselwelt könnte in gewisser Weise als die erste überlieferte Karte der Karibik angesprochen werden. Doch handelt es sich im Grunde nicht um eine kartographische Repräsentation, sondern um eine hochgradig stilisierte - da heraldischen Zwecken dienende - Darstellung einer Vielzahl von Inseln, die offenkundig einer zusammenhängenden Landmasse vorgelagert sein müssen. Inseln über Inseln bedecken dicht gedrängt diesen Quadranten des kolumbinischen Wappens. Doch sind es im Grunde Inseln unter Inseln, Archipele unter Archipelen: Denn wer könnte bei einer derartigen Karte, die keinerlei zuordenbare Umrisse erkennen lässt, schon bestimmen, ob es sich um eine Inselwelt vor der Küste Amerikas oder vor der Küste Asiens handelt? So sollen auch im Vordergrund der nachfolgenden Überlegungen nicht die intraarchipelischen, sondern die inter- und vor allem transarchipelischen, verschiedene Archipele querenden Beziehungen stehen. Denn diese bilden so etwas wie den Kernbestand einer Vorstellungswelt der TransArea Studies.

Die erste im eigentlichen Sinne kartographische Erfassung der Karibik, die auf uns gekommen ist, erfolgte nur zwei Jahre später und wies einen gänzlich anderen Charakter auf. Es handelt sich um die kostbare, heute im Museo Naval zu Madrid aufbewahrte Weltkarte des Kartographen und „Piloto mayor“ Juan de la Cosa, ${ }^{15}$ der sich als der wohl versierteste Steuermann der spanischen Flotte bei den Expeditionen des Kolumbus, aber auch Amerigo Vespuccis vielfach hervortat. Diese im

\footnotetext{
14 Eine Abbildung dieses Wappens findet sich im „Unsichtbaren Atlas“ des von mir neu edierten Werkes über die Entdeckung der Neuen Welt von Humboldt, Alexander von: Kritische Untersuchung zur historischen Entwicklung der geographischen Kenntnisse von der Neuen Welt und den Fortschritten der nautischen Astronomie im 15. und 16. Jahrhundert [...]. 2 Bde. Frankfurt am Main - Leipzig: Insel Verlag, 2009, Bd. 2, S. 219.
}

15 Vgl. Humboldt, Alexander von: Kritische Untersuchungen, Bd. 2, Abb. 20. 
Jahre 1500 wohl in Puerto de Santa María angefertigte Karte, die erst im 19. Jahrhundert in der Bibliothek des Baron von Walckenaer wieder aufgefunden wurde, zeigt uns auf eine bis heute faszinierende Weise eine kartographisch erstaunlich exakte Aufnahme der zum damaligen Zeitpunkt bekannten Kontinente und Inselwelten. ${ }^{16}$ Auf dieser ersten Karte der Neuen Welt im Weltmaßstab kommt gerade den Archipelen sowie transarchipelischen Beziehungen eine herausgehobene Bedeutung zu.

Juan de la Cosas Mapamundi verzahnt diese Präzision dabei mit seit der Antike tradierten abendländischen Bildvorstellungen von der außereuropäischen Welt, ${ }^{17}$ so dass nicht nur ein detailreiches Kartenbild der Antillen und einiger zirkumkaribischer Festlandsäume entsteht, sondern auch die geostrategische Bedeutung dieser Region im Zentrum des amerikanischen Kontinents sehr deutlich vor Augen tritt. ${ }^{18}$ Die in der Karte aufgepflanzten Herrschaftszeichen zeigen es überdeutlich: Die Karibik wurde für die Spanier in der Tat sehr rasch zum militärischen Aufmarschgebiet und Ausgangspunkt ihrer erfolgreichen Eroberungszüge im Norden, in der Mitte und im Süden des amerikanischen Doppel-Kontinents. Von hier, von dieser amerikanischen Inselwelt aus erfolgte die bewegungsgeschichtliche Übersetzung der spanischen beziehungsweise europäischen Expansion in eine Neue Welt, unter der noch immer der asiatische Kontinent verführerisch glänzte. Und auch wenn Indien auf der Weltkarte des Juan de la Cosa noch nicht verzeichnet war, weil der spanische Kartograph nicht über die diesbezüglichen Informationen der Portugiesen verfügte: Die europäischen Projektionen ferner Weltgebiete setzten Asien und Amerika in eine beiderseitige Beziehung.

Ohne jeden Zweifel bietet das bis heute bewegende kartographische Meisterwerk von Juan de la Cosa das um 1500 sicherlich avancierteste kartographische Bild der Erde (Abb. 3). Es lässt bereits sehr deutlich die Umrisse der Großen wie der Kleinen Antillen mit ihren jeweils vorgelagerten Inseln und Inselchen erkennen. Hier war ein Praktiker am Werk, ein wahrhafter und erfahrener Seemann. Bei keiner anderen der frühneuzeitlichen Weltkarten verschränken sich derart eindrucksvoll

16 Vgl. hierzu Wissenschaft und Transzendenz. Literarische und kartographische Weltentwürfe und das Beispiel der „Carta“ von Juan de la Cosa. In: Soethe, Paulo Astor (Hg., unter Mitarbeit von Giovanna Chaves): Weltgermanistik, Germanistiken der Welt. Begegnungen in Lateinamerika. Bern - Berlin - Bruxelles: Peter Lang Verlag 2020, S. 309-361; sowie das Juan de la Cosa gewidmete Kapitel in meinem Band ReiseSchreiben. Potsdamer Vorlesungen zur Reiseliteratur. Berlin - Boston: Walter de Gruyter 2020.

$17 \mathrm{Zu}$ diesen Bilderwelten vgl. u. a. die zahlreichen Abbildungen in Rojas Mix, Miguel: América imaginaria. Barcelona: Editorial Lumen - Quinto Centenario 1992.

18 Vgl. hierzu auch Cerezo Martínez, Ricardo: La Cartografía Náutica Española de los Siglos XIV, XV y XVI. Madrid: Centro Superior de Investigaciones Científicas 1994, S. 82-83 sowie die dazugehörigen Kommentare. 


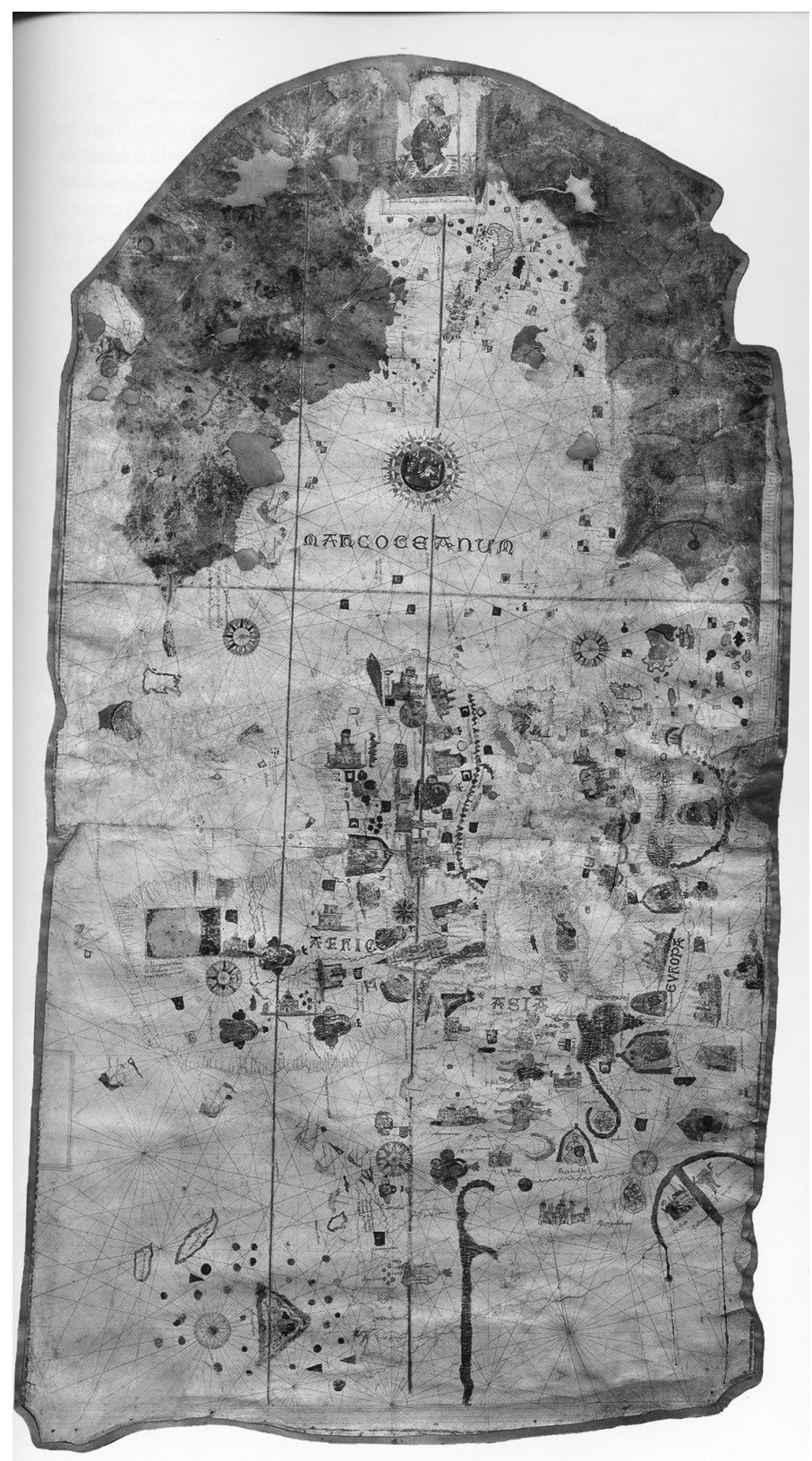

Abb. 3: Juan de la Cosa: Mapamundi, circa 1500. 
kartographische Bildwelten mit den von Antike wie Mittelalter hervorgebrachten beziehungsweise tradierten Weltbildern, wobei diese geradezu unauflösliche Verbindung ihrerseits mit globalen europäischen Machtansprüchen unübersehbar verquickt wird. In die Findung dieser Inselwelt wird die geostrategische Erfindung dieses Raumes im globalen Maßstab gleichsam kryptographisch eingeschrieben. Die Erfindung Amerikas war von den europäischen Vorstellungswelten nicht mehr zu trennen. Vieles von dem, was hier grundgelegt wurde, ging in die Géographie des Lumières, in die Weltsichten des europäischen 18. Jahrhunderts ein. ${ }^{19}$

Juan de la Cosas Opus Magnum frühneuzeitlicher Kartenkunst liefert daher nicht nur ein faszinierendes, auf den eigenen Erfahrungen des großen Steuermannes beruhendes erstes Bild der amerikanischen Hemisphäre im globalen Kontext. Es blendet nicht nur im äußersten Osten Asiens das Land von Gog und Magog ein, sondern skizziert eine Momentaufnahme iberischer Expansionsgeschichte, welche die künftig möglichen Entwicklungslinien einer europäischen Bewegungsgeschichte bereits zu lesen gibt. Auch wenn sich unter dem Wissensdruck der zweiten Phase beschleunigter Globalisierung in der zweiten Hälfte des 18. Jahrhunderts viele Kenntnisstände veränderten: $\mathrm{Zu}$ Beginn des 18. Jahrhunderts basierten noch zahlreiche Vorstellungen auf dieser um 1500 entworfenen Weltkarte und den sich von ihr ableitenden Kartenwerken.

In diesem Zusammenhang ist es spannend $\mathrm{zu}$ beobachten, wie jene Weltkarte des Jahres 1500 die größte der Antillen, die Insel Kuba, bereits acht Jahre nach ihrer Auffindung durch Christoph Kolumbus im Weltmaßstab wiedergibt, hatte Kolumbus Kuba doch teilweise mit dem Cipango des Marco Polo, teilweise aber auch mit der Festlandsmasse des asiatischen Kontinents identifiziert. Diese Tatsache legt einmal mehr Zeugnis ab von der unauflöslichen Verschränkung des Faktischen mit dem Fiktionalen im Dreieck zwischen Erfundenem, Gefundenem und Erlebtem. Juan de la Cosas Weltkarte lässt Kuba/Cipango - das freilich noch nördlich des Wendekreises des Krebses und damit außerhalb der Tropen eingezeichnet ist - im Verbund mit den anderen Inseln der Karibik zum ersten Mal als potenziell globale Insel entstehen. ${ }^{20}$

Es steht angesichts präziser Forschungen über die erste Phase beschleunigter Globalisierung gänzlich außer Frage: Die Karibik wurde - wie Amerika insgesamt - erfunden, bevor sie gefunden wurde. ${ }^{21}$ Die Weltkarte des Jahres 1500 kartographiert damit den Eintritt der Karibik in eine von Europa aus gesteuerte Bewegungsgeschichte, die sich im Übergang vom Mittelalter zur Renaissance in

19 Vgl. hierzu Broc, Numa: La Géographie des Lumières. Paris: Editions Ophrys 1985.

20 Vgl. hierzu Ette, Ottmar: Kuba - Insel der Inseln. In: Ette, Ottmar / Franzbach, Martin (Hg.): Kuba heute. Politik, Wirtschaft, Kultur. Frankfurt am Main: Vervuert Verlag 2001, S. 9-25. 21 Vgl. hierzu den sechsten Band der Aula-Reihe von Ette, Ottmar: Erfunden Gefunden (2022). 
der ersten Phase beschleunigter Globalisierung mit - um den von Goethe geprägten Begriff zu verwenden - velociferischer Geschwindigkeit vollzieht. ${ }^{22}$ Mit guten Gründen wurde in der Forschungsliteratur darauf hingewiesen, dass die Karte des Juan de la Cosa erstmals die geographisch korrekte Position der Äquinoktiallinie sowie des Wendekreises des Krebses angibt. ${ }^{23}$ Folglich ließe sich formulieren, dass die Festlegung des Äquators und die Fixierung der Zentralperspektive ${ }^{24}$ - beiderseits gewiss auf arabischen Grundlagen fußend - fast gleichzeitig erfolgende Erfindungen der Renaissance in Kunst und Kartographie, in Architektur, Malerei und Erdwissenschaft darstellen. Auch an dieser Tatsache mag man ablesen, von welch entscheidender Bedeutung die Karibik für eine Entfaltung des frühneuzeitlichen wie modernen Weltbildes allgemein war.

Vergessen wir dabei aber ein wichtiges ,Detail' nicht: Diese mathematisch und astronomisch fundierten Fiktionen erfolgen vom Abendland aus und für das Abendland. Darin bildet auch das europäische 18. Jahrhundert selbstverständlich keine Ausnahme. Beide Erfindungen erscheinen uns in ihren Hervorbringungen heute - wohlgemerkt aus okzidentaler Perspektive - längst völlig ,natürlich': ganz so, wie wir Photographien unserer Erde aus dem Weltall ,natürlich' nur in genordeter Form zu verbreiten pflegen. Doch handelt es sich bei diesen kunstvoll von Europa aus über die Welt ausgeworfenen Liniensystemen, Kartennetzen und Fokussierungen - wie uns ein Blick auf andere Kulturen zeigt - um kulturelle Kodierungen, die ihre höchst eigene Geschichte und ihre eigenen, wenn auch interkulturell verwobenen Entstehungsbedingungen besitzen und mitreflektieren. Die Kultur ist uns hier zur zweiten Natur geworden. Auch auf diesen Gebieten liegt in der Regel eine Insel unter einer anderen Insel, ein Archipel unter einem anderen Archipel, eine Karte unter einer anderen Karte. Wir müssen nur lernen, diese unterschiedlichen Ebenen voneinander zu trennen beziehungsweise getrennt und gemeinsam zu reflektieren.

Selbstverständlich ist es alles andere als zufällig, dass sich Europa - genauer: die Iberische Halbinsel - mit Blick auf die geographische Länge genau im Zentrum des gewählten Kartenausschnitts wiederfindet. Eine Konstruktion entsteht, in der

22 Vgl. zu der bei Goethe insbesondere zwischen 1825 und 1827 wiederholt auftauchenden Rede von einem „velociferischen Zeitalter“ in Zusammenhang mit Goethes Konzept einer Weltliteratur Bohnenkamp, Anne: „Den Wechseltausch zu befördern“. Goethes Entwurf einer Weltliteratur. In: Goethe, Johann Wolfgang: Ästhetische Schriften 1824-1832. Über Kunst und Altertum V-VI. Hg. v. Anne Bohnenkamp. Frankfurt am Main: Deutscher Klassiker Verlag 1999, S. 937-964.

23 Vgl. Cerezo Martínez, Ricardo: La Cartografía Náutica Española de los Siglos XIV, XV y XVI, S. 82-83 (Abbildungslegende).

24 Vgl. hierzu Belting, Hans: Florenz und Bagdad. Eine westöstliche Geschichte des Blicks. München: Beck 2008. 
sich Europa im Mittelpunkt und zwischen beiden Indien wiederfindet, wie dies noch die ab 1770 verwendete Titelformulierung der großen Kolonialenzyklopädie des 18. Jahrhunderts - Guillaume-Thomas Raynals Histoire philosophique et politique des établissemens et du commerce des Européens dans les deux Indes ${ }^{25}$ - zum Ausdruck bringen sollte. Die Zentralstellung Europas und die Anordnung des Kontinents oben auf den Karten ist keineswegs natürlich, sondern eine Erfindung, die mit derjenigen europäischer Weltkarten einhergeht.

Die Festländer und Archipele Asiens und Amerikas erscheinen so in dem von Juan de la Cosa gewählten Kartenausschnitt an den beiden entgegengesetzten ,Enden' der Welt. Damit werden ein Zentrum, aber auch die Peripherien dieses Zentrums definiert. Insofern ließe sich von einer doppelten Zentrierung (und damit einhergehenden Kodierung) der weltumspannenden Seekarte des Juan de la Cosa sprechen. Es handelt sich um eine Anordnung, die mit ihrer machtpolitisch motivierten Verwendung der Zentralperspektive noch für die Géographie des Lumières grundlegend geworden ist. Und selbst auf den Kartenwerken unserer Tage findet sich diese doppelte Zentrierung nur allzu oft.

Wir sehen folglich ein Zentrum und zwei Peripherien. Mögliche Verbindungen zwischen den asiatischen und den amerikanischen Inselwelten könnten durch den damaligen Kenntnisstand der Europäer und die damit verbundene Wahl des Kartenausschnitts zugleich ausgeschlossen und nahegelegt werden würden sich die ,Extremitäten' des Mapamundi doch bei einer Darstellung in Kugelform wiederum sehr nahe kommen. Doch dann darf man vor dem Hintergrund des hier Dargestellten durchaus behaupten, dass der Archipel der Karibik aus europäischer Sicht von Beginn an transarchipelisch verstanden und kodiert worden ist. Noch war die Weite des Pazifischen Ozeans nicht bekannt, sondern ein Rätsel der europäischen Kartographie; doch erfolgte im 18. Jahrhundert von Europa aus die systematische Erkundung dieser Breiten- und Längengrade, lagen doch nun - in der zweiten Phase beschleunigter Globalisierung - dank der hochpräzisen mobilen Zeitmessung die technologischen Grundlagen für immer genauere Karten bereit.

Von Beginn der europäischen Expansion an gilt die kurz skizzierte transarchipelische Dimension aber selbstverständlich auch und gerade für die transatlantischen Relationen, also in einem Raum, der in der Anordnung des ,atlantischen Längstales“, wie Alexander von Humboldt es nannte, räumlich weit besser als der Pazifik von Europa aus zu überblicken und zu beherrschen war. So ist die Lage ebenso der vor den Küsten Afrikas liegenden Inselgruppen der Kanaren wie auch

25 Vgl. Raynal, Guillaume-Thomas: Histoire philosophique et politique des établissemens et du commerce des européens dans les deux Indes. Genf: Chez Jean-Léonard Pellet, ab 1780. 
der Kapverden nicht nur besonders deutlich markiert und eingezeichnet, sondern auch eine Reihe weiterer Inseln in Juan de la Cosas Carta hervorgehoben. Diese Inseln und Inselgruppen finden sich entweder - wie die zu Portugal gehörende Insel Madeira oder der Archipel der Azoren - auch noch auf unseren heutigen Weltkarten; oder sie stammen aus der langen Traditionslinie der vorwiegend - von der eingezeichneten Insel Tule im Norden aus - nach Westen und Südwesten erfolgenden Projektion imaginärer Inseln. Viele dieser Fiktionen und erfundenen Landoder Meerengen wurden noch bis ins 19. Jahrhundert hinein geglaubt und zeitigten unmittelbare Folgen in der Realität. Noch ein Chateaubriand brach an der Wende zum 19. Jahrhundert auf, um die berühmte Nordwest-Passage und damit die Verbindung zwischen Atlantik und Pazifik im Norden des amerikanischen Doppelkontinents $\mathrm{zu}$ entdecken. ${ }^{26}$

Bald war der schmale Atlantik in Seerouten eingeteilt, die von europäischen Schiffen stets frequentiert wurden. Von der ersten Reise des Kolumbus an führen alle Schiffsrouten in die Karibik stets über die sich vor den Küsten der Alten Welt befindlichen Archipele, um so auf transatlantisch kürzerem, vor allem aber sichererem Wege die auch etymologisch vor-gelagerten ,Gegen-Inseln“ der Antillen, der „Ante-Ilhas“, erreichen zu können. So zeichnen sich auf Juan de la Cosas meisterhafter Karte die vielfachen transarchipelischen Dimensionen einer karibischen Inselwelt ab, die ebenso transatlantisch mit Europa verknüpft wie auch transpazifisch mit Asien verknüpfbar ist. Dazu sollte es genügen, die der Alten Welt entgegengesetzte Küstenlinie der noch unbekannten Neuen Welt jenseits des Atlantiks zumindest teilweise zu erforschen. Bereits wenige Jahrzehnte nach der Eroberung Mexikos wurde die Welt Amerikas über die Philippinen mit Asien in Beziehung gebracht: Ein Vierteljahrtausend lang verband die Galeone von Manila den asiatischen Kontinent über die zu Spanien gehörige Inselgruppe der Philippinen mit dem neuspanischen Hafen von Acapulco, eine Verbindung, die von ungeheurer weltwirtschaftlicher wie künstlerischer Bedeutung war. ${ }^{27}$ Die iberischen Mächte bauten Kolonialsysteme und einen Welthandel auf, die weltumspannenden Zuschnitts waren. Das 18. Jahrhundert ererbt diese Welthandelsstrukturen und fügt von Seiten der neuen Kolonialreiche Frankreichs und Englands eine Reihe weiterer Verbindungssysteme hinzu.

26 Vgl. das Chateaubriand gewidmete Kapitel im vierten Band der Aula-Reihe; Ette, Ottmar: Romantik zwischen zwei Welten. Potsdamer Vorlesungen zu den Hauptwerken der Romanischen Literaturen des 19. Jahrhunderts. Berlin - Boston: Walter de Gruyter 2021, S. 151-176.

27 Vgl. zur großen Bedeutung der sogenannten Biombos sowie der Namban-Kunst Ette, Ottmar: Magic Screens. Biombos, Namban Art, the Art of Globalization and Education between China, Japan, India, Spanish America and Europe in the 17th and 18th Centuries. In: European Review (Cambridge) XXIV, 2 (May 2016), S. 285-296. 
Die geostrategische Relevanz von Inseln und Inselgruppen, die nicht für sich alleine stehen, sondern transarchipelisch stets mit anderen Archipelen verbunden sind und auf andere Inseln verweisen, kann deutlicher kaum vor Augen geführt werden. Von Beginn an bilden die Antillen eine Zone verdichteter Globalisierung, die auch im 18. Jahrhundert unter den Bedingungen der zweiten Phase beschleunigter Globalisierung fortbestehen wird. In der Karibik überschneiden sich die europäischen Machtvektoren zwischen Europa und Asien, zwischen Afrika und Amerika. In diese globale Relationalität und Vektorizität ist sie seit dem Ausgang des 15. Jahrhunderts eingeschrieben. Und noch im 18. Jahrhundert werden sich in der Karibik ebenso weltgeschichtlich wie weltpolitisch fundamentale Geschehnisse ereignen, worunter die Haitianische Revolution am Ende des Jahrhunderts der Aufklärung sicherlich einen Höhepunkt bildet. Wir sollten dabei nicht vergessen, dass der weitaus größte Teil der Erdoberfläche, den wir heute als den karibischen Raum bezeichnen, aus Wasser besteht - und damit aus dem beweglichen Element par excellence. Nicht die statische Territorialität, sondern die Transarealität und Vektorizität sollte daher im Vordergrund unserer gesamten Vorlesung stehen.

Wenn es folglich eine Area auf unserem Planeten gibt, die in höchst verdichteter Form keine eigentliche Raumgeschichte, sondern eine Bewegungsgeschichte repräsentiert, dann ist es die sich hier erstmals abzeichnende Welt des transozeanisch verknüpften Archipels der kolonialen Karibik. Auch andere Kartenwerke des frühen 16. Jahrhunderts - wie etwa die in Straßburg 1513 erschienene Tabula Terre Nove ${ }^{28}$ - machen in ihrem Kartenbild aus heutiger Sicht nicht nur auf die Verschränkungen von Gefundenem, Erfundenem und Erlebtem - wobei sich das Erfundene mit dem Gefundenen auf der Ebene des Erlebten verstrickt -, sondern auf diese fundamental transarchipelische Dynamik einer Relationalität zwischen verschiedenen Inselwelten aufmerksam. In Anlehnung an die französischen Warntafeln an Bahnübergängen können wir daher sagen: „Une île peut en cacher une autre“.

Es liegt daher gleichsam in der Logik dieser historischen und kulturellen Entwicklungen, dass das erste große literarische Zeugnis Kubas, der Espejo de Paciencia, der Geduldsspiegel, von einem Autor stammt, der im Juni 1563 in Las Palmas auf den Kanarischen Inseln das Licht der Welt erblickte. Als junger Mann kam er nach mehreren Reisen zwischen den Kanaren und der Neuen Welt schließlich zusammen mit seinem Bruder Rodrigo auf die Karibikinsel Kuba, wo

28 Tabula Terre Nove. Depromta ex ed. Geographiae Ptolemaei Argentor 1513. Wieder abgedruckt in Humboldt, Alexander von: Kritische Untersuchungen, Bd. 2, Tafel 37. 
er um 1604 Catalina de la Coba heiratete. ${ }^{29}$ Das oft als Gründungstext der kubanischen Literatur apostrophierte epische Gedicht - dem freilich die um wenige Jahre älteren und teilweise Kuba gewidmeten Verse des Langgedichts Florida von Fray Alonso de Escobedo an die Seite zu stellen wären ${ }^{30}$-, ist folglich das Ergebnis nicht nur interarchipelischer Kontakte, sondern transarchipelischer Bewegungen. Und als solches wollen wir es auch analysieren!

Es überrascht daher nicht, dass der Text von Silvestre de Balboa Troya y Quesada, der wohl 1608 abgeschlossen wurde, nicht nur in Kuba seit dem 19. Jahrhundert im Verlauf einer eher verworrenen Rezeptions- und Editionsgeschichte $^{31} \mathrm{zu}$ einem Monument der kubanischen Nationalliteratur stilisiert, sondern später auf den Kanaren aus gutem Grund in die Biblioteca Básica Canaria aufgenommen wurde. Denn der Espejo de Paciencia, im Umfeld der kubanischen Romantik 1838 von José Antonio Echeverría erstmals aufgefunden (oder vielleicht auch erfunden), ${ }^{32}$ ist eine zutiefst transarchipelische lyrische Langform, in deren Zentrum die verschiedenartigsten Bewegungen stehen.

Die schon in den ersten Strophen erfolgende Situierung des Geschehens in Raum und Zeit rückt zweifellos die Insel Kuba ins Zentrum des Geschehens, wobei Schönheit und Reichtum ihrer Natur wie ihrer Naturerzeugnisse topisch und tropisch zugleich besungen werden. Hier beginnen jene Diskurse der Tropen, die sich im Verlauf auch der langen kubanischen Literaturgeschichte in charakteristische Tropen der literarischen Diskurse verwandeln. ${ }^{33}$ Denn die auf den

29 Vgl. zu den biographischen Daten Santana, Lázaro: Prólogo. In: Balboa, Silvestre de: Espejo de Paciencia. Edición de Lázaro Santana. Las Palmas, Islas Canarias: Biblioteca Básica Canaria 1988, S. 9-11; sowie ausführlicher Marrero-Fente, Raúl: Epic, Empire, and Community in the Atlantic World. Silvestre de Balboa's „Espejo de paciencia“. Lewisburg: Bucknell University Press 2008, S. 79-82.

30 Vgl. hierzu Esteban: Angel: „Si no lo veo, no lo creo“: sobre „Florida“ de Escobedo y el „Espejo de Paciencia“. In: Valcárcel, Eva (Hg.): La literatura hispanoamericana con los cinco sentidos. Actas del V congreso Internacional de la AEELH. La Coruña: Universidad de La Coruña 2002, S. $208 \mathrm{f}$.

31 Vgl. zu der im Gedicht selbst angelegten Lesersteuerung Marrero-Fente, Raúl: Teoría y práctica de la épica en la dedicatoria y prólogos de „Espejo de paciencia“ de Silvestre de Balboa. In: Bulletin of Spanish Studies (Glasgow) LXXX, 3 (May 2003), S. 309-322.

32 Vgl. hierzu Vitier, Cintio: Prólogo. In: Balboa, Silvestre: Espejo de Paciencia. Las Villas: Universidad Central de Las Villas 1960, S. 7.

33 Vgl. hierzu Ette, Ottmar: Diskurse der Tropen - Tropen der Diskurse: Transarealer Raum und literarische Bewegungen zwischen den Wendekreisen. In: Hallet, Wolfgang / Neumann, Birgit (Hg.): Raum und Bewegung in der Literatur. Die Literaturwissenschaften und der Spatial Turn. Bielefeld: transcript Verlag 2009, S. 139-165. 
29. April 1604 datierbaren Ereignisse der Gefangennahme und Entführung des Bischofs der Insel Kuba, Fray Juan de las Cabezas Altamirano, durch französische Piraten unter der Führung von Gilbert Giron werden im kleinen Flecken Yara unweit des Hafens von Manzanillo im kubanischen Oriente angesiedelt. Sie handeln buchstäblich in einem blühenden Garten, in einem tropikalisierten locus amoenus, dessen Vorläufer sich selbstverständlich in Cristóbal Colóns Diario de a bordo finden. Wieder ist wie schon bei Marco Polo oder Cristoforo Colombo die Fülle in aller Exuberanz für die Tropenlandschaft charakteristisch. Der Diskurs der Tropen ist quasi installiert:

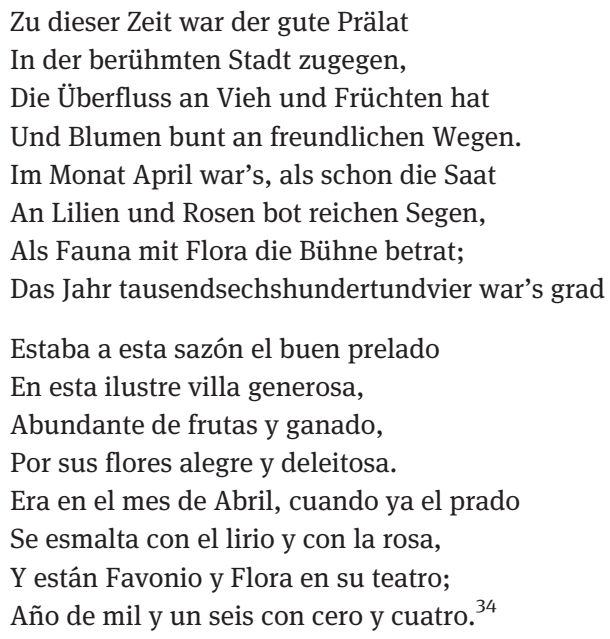

Dass der Espejo de Paciencia ebenso die Insularität wie die spezifische Inselnatur entfaltet, wurde bereits vielfach als wichtiger Ausgangspunkt einer sich im Grunde erst am Ausgang des 18. Jahrhunderts entfaltenden „cubanía“ gedeutet, eines spezifisch kubanischen Selbstverständnisses. ${ }^{35}$ Es waren gerade die Dichter aus dem Umkreis der Orígenes-Gruppe um José Lezama Lima und allen voran Cintio Vitier, die nicht müde wurden, das essentiell Kubanische in der kubanischen Lyrik immer wieder auf diesen Text zurückzuführen. Dieser sei „penetrado de una luz matinal de playa y de un aroma de frutos cubanos que nos hacen encantadores hasta sus desaliños verbales“: ${ }^{36}$ Alles riecht und duftet

34 Balboa, Silvestre: Espejo de Paciencia, S. 45.

35 Vgl. hierzu u. a. Sáinz, Enrique: Nuestro primer poema: „Espejo de paciencia“. In: Prats Sariol, José (Hg.): Nuevos críticos cubanos. Selección y prólogo de José Prats Sariol. Havanna: Editorial Letras Cubanas 1983, S. 33-50.

36 Vitier, Cintio: Lo cubano en la poesía. Havanna: Instituto del Libro 1970, S. 26. 
nach den wunderbaren Essenzen der Kubanität auf einer Insel, an deren tropischen Stränden das Meer rauscht.

Zugleich aber scheint mir das Argument von Lázaro Santana nicht von der Hand $\mathrm{zu}$ weisen $\mathrm{zu}$ sein, dass die in den Espejo de paciencia aufgenommenen Beschreibungen einer exuberanten Natur nicht zuletzt auf die Tatsache zurückgeführt werden können, dass der Poet des Piraten-Epos, mithin Silvestre de Balboa, als Kanare einerseits mit einer außereuropäischen Natur im Zeichen der Fülle bestens vertraut war. Andererseits kannte er literarische Vorbilder von den Kanarischen Inseln, die - wie der Templo Militante (1602) von Cairasco oder das Poema (1604) von Viana - für diese Fülle bereits poetische Ausdrucksformen gesucht und gefunden hatten. ${ }^{37}$ So ließe sich im Rückgriff auf diese doppelte (also nicht nur ,natürliche“ beziehungsweise naturhafte, sondern auch literarische) Beziehung eine spezifische Vorliebe für die sinnliche, aisthetische Qualität des Benennens gleichsam transarchipelisch begründen: „Diese drei Dichter belegen die reine Freude daran, die Sprache in ihrer eigentlichsten Manifestation zu verwenden: mit dem Wort an sich. Kein Adjektiv nuanciert, exaltiert oder bremst. Frank und frei wird der Einbildungskraft des Lesers eine Welt von Fruchtfleisch und Feuchtigkeit, von Farben und Berührungen, von Geschmacksrichtungen geboten allein vermittels der demiurgischen und simplen Tatsache des Benennens. “38

Diese transarchipelische, zwischen Kuba und den Kanaren oszillierende Logik erschließt sich auch jenseits der recht aufschlussreichen Lexik poetischer Benennungen. Immer wieder finden sich Bezugnahmen auf andere (altweltliche) Inselwelten, welche - gewiss vom Nachnamen des Verfassers beflügelt Troja und das Archipel der griechischen Inseln zwischen ,Europa' und ,Asien“ gleich in den ersten beiden Versen von Balboa Troya y Quesada einblenden. ${ }^{39}$ Aber auch die Kanaren werden früh schon als Vergleichspunkt eingeführt, ${ }^{40}$ so dass der transarchipelischen Genese bei aller Ausrichtung an Kuba auch eine transarchipelische Diegese und Horizonterweiterung entspricht. Der Espejo de paciencia situiert sich voll und ganz im Bewegungsraum zwischen der karibischen und der kanarischen Inselwelt, zwischen Europa, Afrika und Amerika.

37 Vgl. Santana, Lázaro: Prólogo, S. 14f.; dort findet sich auch ein kurzer Textvergleich mit Viana und Cairasco. Zur Bedeutung insbesondere von Cairasco vgl. ebda., S. 18.

38 Ebda., S. 15: „Los tres poetas revelan el puro goce de utilizar la lengua en su manifestación más genuina: la palabra por sí misma. Ningún adjetivo matiza, exalta o refrena. Limpiamente se propone a la imaginación del lector un mundo de pulpas y humedades, colores y tactos, sabores, con el hecho demiurgo y simple de nombrar.“

39 Balboa, Silvestre: Espejo de Paciencia, S. 43.

40 Ebda., S. 49. 
Nach der Auslösung des Bischofs durch massive Lösegeldzahlungen an den wiederholt als „luterano“ bezeichneten französischen Freibeuter erfolgt eine gewiss antikisierende Inszenierung eines kubanischen Garten Eden, der mit all seinen tropischen Früchten und Erzeugnissen in Szene gesetzt wird: „Vienen cargadas de mehí y tabaco, / Mameyes, piñas, tunas y aguacates, / Plátanos y mamones y tomates. “41 Nichts an Früchten und tropischen Gewächsen darf in diesem Versepos fehlen. Aber auch Nymphen und Zentauren schließen sich am Ende des Ersten Gesangs von Silvestre de Balboas Langgedicht dem buntem Reigen jener Feier an, die nicht nur die Freilassung des katholischen Bischofs zelebriert, sondern zugleich ganz selbstverständlich die griechische Inselwelt in die Karibik transportiert und über-setzt. Das Bild der Insel ist mit dem namengebenden Archipel, mit der Inselwelt Griechenlands, untrennbar verbunden.

Die Asymmetrie dieser transatlantischen Beziehungen ist ebenso auf der politischen, militärischen und sozialen wie auf der kirchlichen, kulturellen und literarischen Ebene evident. Und diese Asymmetrie im transarealen Wechselspiel könnte nicht schärfer ausgeprägt sein. So bündeln sich im Espejo de Paciencia jene Vektorenfelder und Vektoren, die eine Geschichte dieses Raumes nur in Form einer relationalen Bewegungsgeschichte als sinnvoll erscheinen lassen. Gerade hierin aber scheint mir der Espejo de Paciencia ein gutes Stück karibischer Literaturgeschichte zu sein: als Teil der Geschichte einer Literatur, die niemals nur von einem einzigen Ort, von einer einzigen Insel aus zu denken ist. Das Versepos inauguriert eine Literatur, die zu keinem Zeitpunkt als statische zu verstehen ist: Alles bildet sich in der Area der Karibik aus Wechselbeziehungen und Bewegungen heraus.

Die Anrufung an die weltweit verstreuten Soldaten der Weltmacht Spanien, die den Canto Segundo eröffnet - „Valientes caballeros que en Bretaña, / Flandes, Italia y otras cien mil partes, / En honra de Filipo, rey de España, / Enarboláis banderas y estandartes“42 -, unterstreicht nicht nur die Ansprüche der nach dem Untergang der spanischen Armada angeschlagenen Kolonialmacht. Denn sie spannt auch einen Verstehens-Horizont auf, innerhalb dessen die Bekämpfung des französischen ,Lutheraners“ in der Karibik ganz selbstverständlich in globale Zusammenhänge und Kriegsszenarien eingerückt wird. Das Langgedicht weiß sich all jenen Soldaten verbunden, die für die Sache Spaniens in der Bretagne, in Flandern oder in Italien, aber auch auf tausend anderen Kriegsschauplätzen kämpfen.

41 Ebda., S. 58.

42 Ebda., S. 69. 
Das in derartigen Passagen literarisch in Szene gesetzte Weltbewusstsein des von den Kanaren stammenden Autors beruht nicht auf einer wie auch immer gearteten kontinentalen, also an einer kontinuierlich zusammenhängenden Territorialität ausgerichteten Vorstellung, sondern auf einem mit unendlich vielen Orten und Räumen in Verbindung stehenden Insel-Selbstbewusstsein, das an tausenderlei Orten diskontinuierlich die „cien mil partes“ iberischer Machtpräsenz zusammendenkt. Wie die spanische Expansion ausgehend von der Karibik eine insulare Logik entwarf, mit deren Hilfe der amerikanische Kontinent von dort aufgebauten Machtinseln städtischer Zentren unterworfen und kontrolliert wurde, so zeigt sich auch im Espejo de Paciencia insgesamt, dass die von ihm entfaltete Logik eine transarchipelische ist, die anders als im Norden des Kontinents keiner territorial vorrückenden „frontier“ verpflichtet scheint. Diese Grundunterscheidung zwischen einer archipelisch und einer kontinental vorrückenden Grenze eigener Macht hebt die Unterschiede zwischen den einzelnen Kolonisierungsstrukturen auf dem amerikanischen Kontinent hervor.

So tritt der mutige Spanier, der „valeroso hispano“, 43 Gregorio Ramos als Rächer in Erscheinung, der sich in einem weltweiten Kampf gegen verschiedenartigste Formen der Häresie, eines „herético concilio“, ${ }^{44}$ weiß und sich aller häretischen Verschwörungen zum Trotz bewährt. Die sich über lange Verse erstreckende Vorstellung der Helden des Rachefeldzuges zeigt, wie irreführend eine statisch-territoriale Sichtweise nicht nur dieser Episode der Geschichte in der Karibik wäre: „De Canarias, Palacios y Medina / Pasan armados de machete y dardo, / Juan Gómez, natural, con punta fina, / Y Rodrigo Martín, indio gallardo; / Cuatro etïopes de color de endrina; / Y por la retaguardia, aunque no tardo, / Va Melchor Pérez con aguda punta. “45 Wir haben es mit Spaniern von der Halbinsel und mit Kanaren, mit indigenen Helfern und mit Schwarzen, mit „Äthiopiern“, zu tun, welche allesamt für die Sache Spaniens aufgeboten werden. Indianer, Afrikaner und Europäer, in Spanien, in Kuba wie auf den Kanaren Geborene setzen es sich zum bald schon erreichten Ziel, dem verhassten Franzosen den Kopf abzuschlagen. Daran wird nicht nur die hohe Mobilität von Freibeuterei und Piraterie, sondern auch jene der Bewohner der Neuen Welt, des „Nuevo Mundo“46 deutlich - zu denen im Gedicht auch Italiener, Franzosen und Portugiesen zählen. Europa hat in Amerika die Herrschaft übernommen, hat sich zugleich aber fundamental in der transatlantischen Übersetzung verändert.

43 Ebda., S. 63.

44 Ebda.

45 Ebda., S. 67.

46 Ebda., S. 63. 
In dieser nur bewegungsgeschichtlich, nicht aber statisch-raumgeschichtlich zu verstehenden Dimension liegt aus der hier gewählten Perspektive die eigentliche Bedeutung des Espejo de Paciencia, fängt er für uns in seinem Spiegel doch das Weltbewusstsein einer noch in der Kontinuität der ersten Phase beschleunigter Globalisierung stehenden Bevölkerung ein, für die das Territoriale vorrangig als Bewegungs-Raum erscheint. Lange noch ist hierfür der Terminus nicht gefunden, der in Kuba um 1940 erfunden wird: Doch die transkulturelle Transformation dieser Bevölkerung hat längst begonnen. ${ }^{47}$ So beeindruckt bis heute die Tatsache, dass das höchste Lob von Silvestre de Balboas Versepos jenem schwarzen Sklaven gilt, dessen Freilassung gefordert wird, da er es war, der den Anführer der französischen Piraten Gilbert Giron in edlem Kampfe besiegt hatte:

Kreole Salvador, Du ehrbarer Schwarzer,

Dein Ruhm erschallt und wird niemals vergehen:

Dir gutem Soldaten voller Lob, voll Ehr,

Töne Dein Ruf, mag Schrift nie verwehen.

Nicht weil ich es sagte aus diesem Karzer,

Kein Sterblicher mag es je missverstehen,

Aus Zuneigung schrieb' ich's, für Dich, Du Schwarzer,

Der Du Sklave, grundlos gefangen, magst fortbestehen.

¡Oh, Salvador criollo, negro honrado!

Vuele tu fama y nunca se consuma:

Que en alabanza de tan buen soldado

Es bien que no se cansen lengua y pluma.

Y no porque te doy este dictado,

Ningún mordaz entienda ni presuma

Que es afición que tengo en lo que escribo

A un negro esclavo y sin razón cautivo. ${ }^{48}$

In diesem Hymnus auf einen Schwarzen entsteht das Bild einer Konvivenz, eines friedlichen Zusammenlebens unterschiedlicher Ethnien und Kulturen auf der Insel Kuba. Mit diesen Versen entwirft Silvestre de Balboas Espejo de Paciencia in poetischer Form eine ,vision of the community“ und zugleich die „poetics of community“, ${ }^{49}$ welche die Möglichkeiten eines künftig einträchtigen Zusammenlebens der ethnischen und kulturell so unterschiedlichen Bevölke-

47 Zum Begriff der Transkulturalität vgl. Ortiz, Fernando: Contrapunteo cubano del tabaco y el azúcar. Prólogo y Cronología Julio Le Riverend. Caracas: Biblioteca Ayacucho 1978.

48 Balboa, Silvestre: Espejo de Paciencia, S. 75.

49 Marrero-Fente, Raúl: Epic, Empire, and Community in the Atlantic World. Silvestre de Balboa's „Espejo de paciencia“, S. 175. 
rungsteile auf der Insel skizzieren. Mit guten Gründen ließe sich daher sagen, dass in diesen Versen eines karibischen Versepos von 1608 in verdichteter Form ein Zusammenlebenswissen ${ }^{50}$ - wenn auch noch vorsichtig - erkundet wird, das die Bewegungslinien eines transarealen Raumes zwischen Europa und Amerika, Afrika und Asien zusammenführt. Denn ein schwarzer Sklave wird zum Helden eines Epos, das die Gemeinschaft eines in den Tropen gelegenen blühenden Gemeinwesens in den Mittelpunkt rückt.

Der Espejo de paciencia zeitigte vielfältige Folgen, gerade auch im Bereich der Literatur. Dass diese in der Region von Bayamo angesiedelte Szenerie im weiteren Verlauf der kubanischen wie der karibischen Geschichte zugleich das Zeug hatte, zum symbolischen Akt des Widerstands gegen von außen angreifende und eindringende Mächte stilisiert werden zu können, zeigt der die kubanische Geschichte aus einer karibischen Perspektive durchlaufende Text Le Roman de Cuba. Letzteren legte der mit der Nachbarinsel Kuba sehr verbundene und mit einer Arbeit über Alejo Carpentier promovierte haitianische Schriftsteller Louis-Philippe Dalembert Anfang 2009 vor. Dort stoßen wir auf das Kapitel „Playa Girón, l'histoire d'un pirate français trop arrogant“, in welchem die Ereignisse von April 1604 unmittelbar mit der vom CIA gelenkten, gegen die Revolution Fidel Castros gerichteten, aber rasch in sich zusammengebrochenen Invasion von April 1961 in der Schweinebucht, dem heutigen Playa Girón, verknüpft werden:

Im Gemenge findet sich Giron von Angesicht zu Angesicht mit dem Sklaven Salvador Golomón wieder, einem kreolischen Schwarzen, der also auf der Insel zur Welt kam. Bevor Giron noch die Zeit fand, seine Muskete zu laden, stieß ihm dieser seine Lanze durch die Brust. Der Franzose wird zu Boden gestreckt. Und Salvador Golomón stürzt sich auf ihn, um ihm den Gnadenstoß zu versetzen. Danach schnitt er ihm mit der Machete den Kopf ab. Als sie sahen, dass ihr Anführer tot war, ergriffen die zwei oder drei Halunken, die noch am Leben waren, rasch die Flucht. Der Kopf des Franzosen wird auf dem Hauptplatz von Bayamo aufgepflanzt. Auf diese Weise ging die Karriere des französischen Piraten Gilbert Giron zu Ende, der seinen Namen jenem Strand gab, an dem er mit seinen Gefährten an Land ging. ${ }^{51}$

Mochte die Karriere von Gilbert Giron damit auch zu Ende gegangen sein, diejenige der Korsaren und Freibeuter im gesamten Raum der Karibik war es nicht. Denn gerade im 18. Jahrhundert errichteten die „Brüder der Küste“ ein stabiles und wehrhaftes Gemeinwesen, das den europäischen Kolonialmächten und deren Abtransporten amerikanischer Reichtümern noch lange Zeit Paroli bieten konnte.

50 Vgl. zu dieser Begrifflichkeit Ette, Ottmar: ZusammenLebensWissen. List, Last und Lust literarischer Konvivenz im globalen Maßstab (ÜberLebenswissen III). Berlin: Kulturverlag Kadmos 2010; sowie (ders.): Konvivenz. Literatur und Leben nach dem Paradies. Berlin: Kulturverlag Kadmos 2012.

51 Dalembert, Louis-Philippe: Le Roman de Cuba. Monaco: Editions du Rocher 2009, S. 74. 
Doch können wir in unserer Vorlesung der reizvollen und spannenden Geschichte der Freibeuter, Korsaren und Piraten leider nicht weiter nachgehen - auf diesem Gebiet hat sich in den letzten Jahrzehnten eine eindrucksvolle Forschung entwickelt. ${ }^{52}$ Aber eine Frage blieb doch: War die Geschichte um den heldenhaften schwarzen Salvador nicht einfach zu schön, um wahr zu sein?

Seit den ersten Nachrichten von der ,Entdeckung‘ des Espejo de Paciencia in den Archiven der Sociedad Patriótica de La Habana wurde immer wieder der Verdacht geäußert, dass es sich bei dieser Auffindung eher um eine Erfindung gehandelt habe. Diese sollte dazu dienen, für die kubanische Literatur und mehr noch für das Unabhängigkeitsstreben der Insel Kuba eine ebenso respektable wie jahrhundertealte Genealogie zu schaffen. ${ }^{53}$ Gewiss konnte trotz vieler Versuche der Beweis für diese These bisher noch niemals schlüssig erbracht werden. Doch selbst wenn sich dieser Verdacht, der wiederum in Romanform von dem kubanischen Schriftsteller Leonardo Padura in La novela de mi vida im Jahre 2002 ins Spiel gebracht wurde, eines Tages bestätigen sollte: Er würde aus der hier gewählten Perspektivik im Grunde nur beweisen, dass die nachträgliche Konstruktion der langanhaltenden Herausbildung einer wie auch immer gearteten essentiell ,kubanischen Identität‘ nicht ohne die Grundierung einer transarchipelischen Relationalität möglich gewesen wäre.

Denn im Espejo de Paciencia verschränken sich die Dimensionen des Erfundenen und des Gefundenen auf fundamentale Weise miteinander, um sich auf ein Erlebtes und zugleich Nacherlebbares hin zu öffnen, das sich im Verlauf einer langen Rezeptionsgeschichte zu entfalten vermag. Nicht selten hat das Erfundene in der Realität eine stärkere Ausstrahlungs- und Wirkkraft als das Gefundene: Wir leben alle eingebettet in Fiktionen, die für uns die Realität bedeuten. Der peruanische Literaturnobelpreisträger Mario Vargas Llosa hat diese Einsicht mit dem Hinweis versehen, dass es da noch immer besser sei, den wirklich guten (also den literarischen) Fiktionen anheimzufallen als den schlechten, den „malas ficciones“, die aber - wie die Börsendaten und in unseren Gesellschaften auch die Verschwörungsideologien - vielen Menschen wie Tatsachen erscheinen, welche das jeweilige Handeln bestimmen. Sie regieren beträchtliche Teile unseres Lebens, auch wenn wir dies nicht immer vor Augen haben.

52 Vgl. etwa Arnold, Albert James: Corsaires, Aventuriers, Flibustiers et Pirates: Identités Régionales à la frontière de l’Empire Espagnol dans la Caraïbe. In: Ette, Ottmar / Müller, Gesine (Hg.): Caleidoscopios coloniales. Transferencias culturales en el Caribe del siglo XIX. Kaléidoscopes coloniaux. Transferts culturels dans les Caraïbes au XIX ${ }^{e}$ siècle. Madrid - Frankfurt am Main: Iberoamericana - Vervuert 2010, S. 213-227.

53 Vgl. hierzu auch Esteban, Angel: „Si no lo veo, no lo creo“: sobre „Florida“ de Escobedo y el „Espejo de Paciencia“, S. 205-210. 
Nehmen wir daher für einen kurzen Augenblick an, dass der Espejo de paciencia eine geschickte Fälschung und Erfindung wäre, die von irgend einem kubanischen Autor des ausgehenden 18. Jahrhunderts oder der ersten Hälfte des 19. Jahrhunderts erfunden wurde! Wäre dies aber dann nicht der beste Beleg dafür, dass die Karibik im Grunde nur als Archipel begreifbar ist, hinter dem sich ständig andere Archipele, andere Inselwelten verbergen?

Denn es kann kein Zweifel daran bestehen, dass der karibische Raum dank der Intensität seiner transozeanischen Verbindungen einen Bewegungs-Raum darstellt, der ohne seine viellogische $e^{54}$ Relationalität, aber auch seinen großen Reichtum auf allen Ebenen nicht adäquat gedacht werden kann. Schauen wir auf das Jahrhundert der Aufklärung, das „Siècle des Philosophes“, so heißt es im zehnten Buch der bereits erwähnten Histoire des deux Indes von Guillaume-Thomas Raynal mit Blick auf jenen Raum, den wir heute die Karibik nennen: „Amerika schließt zwischen dem achten \& dem zweiunddreißigsten Grad nördlicher Breite den zahlreichsten, den umfangreichsten und den überhaupt reichsten Archipel mit ein, den der Ozean jemals der Neugier, der Tatkraft und der Habgier der Europäer dargeboten hat.“55

In seiner Darstellung des karibischen Raums bezieht der aus dem südfranzösischen Rouergat stammende Abbé Raynal daher von Beginn an die Frage nach der infrastrukturellen Anbindung dieser Inselwelt an die Häfen der verschiedenen europäischen Mutterländer wie auch die Problematik ihrer Vernetzung mit den Küsten Afrikas mit ein. Indem er diesem Aspekt breiten Raum in seiner aufklärerischen Kolonialenzyklopädie gibt, entwirft er einen komplexen, nicht nur transatlantischen, sondern transozeanischen Bewegungsraum, innerhalb dessen Netzwerk die karibische Inselwelt seit der ersten Phase beschleunigter Globalisierung eine wichtige, ja entscheidende Rolle spielt. Die Histoire des deux Indes führt mitten in der zweiten Phase beschleunigter Globalisierung eindrucksvoll vor Augen, von welcher Bedeutung diese transarchipelisch vernetzten Transport- und Wirtschaftswege sind, die im Übrigen in den aufgeklärten Kolonialmächten Europas die Gewinne und Profite durch den barbarischen Sklavenhandel hochschnellen ließen.

Mit Hilfe zahlreicher Statistiken versucht der später in der Französischen Revolution als Vorläufer gefeierte Raynal akribisch genau, die sich innerhalb

54 Zum literatur- und kulturtheoretischen Potential des Polylogischen vgl. Ette, Ottmar: Viellogische Philologie. Die Literaturen der Welt und das Beispiel einer transarealen peruanischen Literatur. Berlin: Verlag Walter Frey - edition tranvía 2013.

55 Raynal, Guillaume-Thomas: Histoire philosophique, Bd. 5, S. 197: „L’Amérique renferme, entre le huitième \& le trente-deuxième degré de latitude septentrionale, l'archipel le plus nombreux, le plus étendu, le plus riche que l'océan ait encore offert à la curiosité, à l'activité, à l'avidité des Européens.“ 


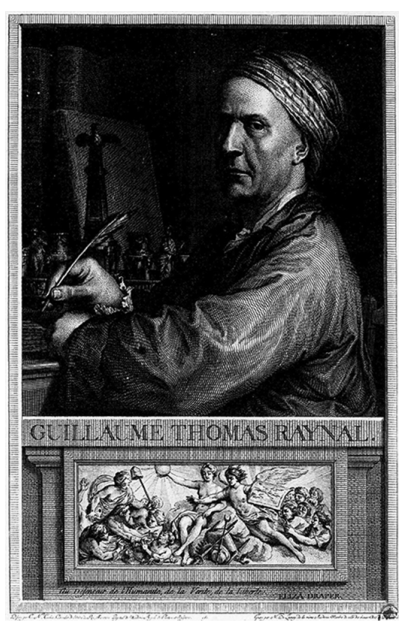

Abb. 4: Nicolas de Launay: Guillaume-Thomas Raynal (1713-1796).

jener strukturellen Veränderungen und Verschiebungen, welche die zweite Phase beschleunigter Globalisierung in der zweiten Hälfte des 18. Jahrhunderts ausmachen, deutlich abzeichnenden Preisschwankungen der „terms of trade“ nachzuvollziehen. Seine Philosophische und politische Geschichte der Niederlassungen und des Handels der Europäer in beiden Indien bezeugt die ungeheure Kraft, welche in dieser Globalisierungsphase insbesondere von den neuen Führungsmächten Frankreich und England entfesselt wurde. Die Konsequenzen all dieser Bewegungen ergeben sich aus seiner Sicht geradezu zwangsläufig aus dem von Europa gesteuerten Prozess globaler Vernetzung und weltweiter Ausbeutung, der auch die künstliche Erzeugung einer Nachfrage nach Luxusgütern wesentlich miteinschließt. Sehen wir uns die in der Histoire des deux Indes vorgebrachten Argumentationen einmal näher an:

Auch wäre der Sklavenhandel schon zusammengebrochen, wenn die Bewohner der Küsten nicht längst ihren Luxusbedarf an die Völker im Binnenlande weitergegeben hätten, von denen sie heute den Großteil der Sklaven nehmen, welche sie uns liefern. Auf diese Weise hat der Handel der Europäer die für den Handel verwertbaren Reichtümer nahezu vollständig erschöpft.

Diese Erschöpfung hat den Preis der Sklaven innerhalb von zwanzig Jahren nahezu vervierfacht; \& auf diese Weise ging es vonstatten. Man bezahlt sie zum allergrößten Teil mit Handelswaren aus Ostindien, die ihren Wert in Europa verdoppelt haben. In Afrika muss man wiederum das Doppelte für diese Handelswaren bezahlen. So sind die Kolonien in Amerika, wo sich der letzte Teil des Handels vollzieht, gezwungen, diese unterschiedlichen Erhöhungen zu ertragen \& zahlen folglich viermal mehr als früher.

Allerdings erhält der weit entfernte Eigentümer, der seinen Sklaven verkauft, weniger Handelswaren, als vor fünfzig Jahren derjenige dafür bekam, der den Seinigen in der Nachbarschaft der Küste verkaufte. Der Profit der Zwischenhändler; die Kosten für die 
Verbringung, die Begleichung der Rechte, denn bisweilen muss man drei Prozent den Herrschern bezahlen, deren Gebiete man quert, all dies absorbiert die Differenz zwischen der Summe, welche der erste Eigentümer erhält, und dem, was der europäische Händler letztlich bezahlt. ${ }^{56}$

Wir erhalten in diesen Erläuterungen eine genaue Darstellung der Mechanismen, Bedingungen und Profitmargen jenes transatlantischen Sklavenhandels, den die europäischen Kolonialmächte zwischen Europa, Afrika und ihren Kolonien in Amerika höchst profitabel etablierten. Auf der Basis vielfältiger Quellen und Dokumente berechnet Raynal die erheblichen Kostensteigerungen, aber auch die exorbitanten Verdienstmöglichkeiten für alle, die mittelbar oder unmittelbar am Handel mit schwarzen Sklaven beteiligt waren oder mit ihrem Kapital auf diesem Markt (wie wohl er auch selbst) spekulierten. Raynal erblickt in der ständigen Verteuerung der Sklaven, die aus immer entfernteren Gebieten Afrikas herbeigeschafft werden müssen, die - wie wir heute wissen - illusorische Möglichkeit, dass der Sklavenhandel sich damit aus wirtschaftlichen Gründen selbst abschaffen könnte. Doch wird auch deutlich, dass der Verfasser und Herausgeber der Histoire philosophique et politique des établissemens et du commerce des Européens dans les deux Indes ${ }^{57}$ die weltumspannende Dimension des Black Atlan$\mathrm{tic}^{58}$ überaus realitätsnah darzustellen verstand.

Die vom Abbé Raynal mit Hilfe eines weltweiten Korrespondenten-Netzes zusammengetragenen und gemeinsam mit vielen anderen Autoren herausgegebenen Daten machen seine Kolonialenzyklopädie auch heute noch zu einer wahren Fundgrube für die Beleuchtung zeitgenössischer Wirtschaftsdaten rund um den abscheulichen und unmenschlichen Sklavenhandel. Dem Titel seiner großen Kolonialenzyklopädie gemäß, gelingt es Raynal in seiner Histoire des deux Indes, den Sklavenhandel, die „traite des noirs“, als ein globales Phänomen zu porträtieren. In diesem ist die von Europa aus gelenkte Verschleppung von Millionen schwarzer Sklaven von Afrika nach den „Indes Occidentales“ (also Amerika) aufs Engste verzahnt ist mit dem Handel Europas mit den „Indes Orientales“ (also Asien).

Unser Blick geht zurück zur Weltkarte des Juan de la Cosa, in welcher diese allgemeine Anlage der beiden peripheren Indien mit ihren in Zukunft von Europa abhängigen Kolonialstrukturen zum ersten Mal kartographisch erfasst wurden.

56 Ebda., Bd. 6, S. 69.

57 Vgl. hierzu auch Ette, Ottmar: Diderot et Raynal: l'oeil, l'oreille et le lieu de l'écriture dans l',Histoire des deux Indes“. In: Lüsebrink, Hans-Jürgen / Strugnell, Anthony (Hg.): L',Histoire des deux Indes": réécriture et polygraphie. Oxford: Voltaire Foundation 1996, S. 385-407.

58 Vgl. hierzu Gilroy, Paul: The Black Atlantic. Modernity and double consciousness. London: Verso 1993; sowie Der Black Atlantic. Herausgegeben vom Haus der Kulturen der Welt in Zusammenarbeit mit Tina Campt und Paul Gilroy. Berlin: Haus der Kulturen der Welt 2004. 
Wir kommen nicht umhin, dieser frühen Karte, welche den Katholischen Königen Spaniens erstmals einen Überblick über ihr entstehendes Reich auf diesem Planeten verschaffen sollte, eine enorm prospektive Bedeutung beizumessen. Was in der ersten Phase beschleunigter Globalisierung an Kolonialräumen für europäische Mächte erschlossen ward, wurde in der zweiten Phase wesentlich ausgeweitet, vor allem aber dank neuer Technologien intensiviert. So zeigt sich auch in diesem Kontext des Jahrhunderts der Aufklärung, wie sehr die karibische Inselwelt in nochmals verstärktem Maße während der zweiten Phase beschleunigter Globalisierung nicht nur mit Europa und Afrika sowie den Afrika vorgelagerten Archipelen verbunden blieb, sondern zugleich in ein auch Asien umfassendes komplexes System von Handelswegen eingebunden war. Längst waren diese Handelswege und der mit ihnen einhergehende Weltverkehr in und für Europa selbstverständlich geworden. Dies ist die Hintergrundfolie, auf der wir stets das 18. Jahrhundert betrachten sollten: nicht als eine weit im Hintergrund stehende wirtschaftliche oder politische Marginalie, sondern als die Basisstruktur, auf der sich alles entwickelte.

Dabei ist es keineswegs so, dass in dieser Kolonialenzyklopädie des 18. Jahrhunderts die wirtschaftlichen Mechanismen nur teilnahmslos und sachlich beschrieben würden. Die von der Feder Denis Diderots, des sicherlich wichtigsten Mit-Autors, so häufig in der Histoire des deux Indes vorgetragene Verurteilung des Sklavenhandels wie des europäischen Kolonialismus fehlt daher gerade in den der Karibik gewidmeten Teilen des Raynal'schen Werkes - wie anhand vieler anderer Passagen zu zeigen wäre - keineswegs. Denn schon zu Beginn wird die Entdeckung und Eroberung Amerikas und damit die erste Phase beschleunigter Globalisierung als Anfang allen Übels verflucht:

Verflucht sei daher der Augenblick ihrer Entdeckung! Und Ihr, Ihr Herrscher Europas, was kann der Beweggrund für Eure eifersüchtige Ambition zugunsten von Besitzungen sein, deren Elend Ihr nur in alle Unendlichkeit verlängern könnt? \& welche Ihr nicht sich selbst wieder zurückgebt, wenn Ihr daran verzweifelt, sie zum Glücke zu führen! Im Verlaufe dieses Werkes habe ich es mehr als ein Mal gewagt, Euch die Mittel dafür anzugeben: Aber ich fürchte wohl, dass meine Stimme nur in der Wüste schrie \& noch immer schreit. $^{59}$

Die Histoire des deux Indes ist in mehr als nur einer Hinsicht ein für das europäische 18. Jahrhundert charakteristischer und mithin stark schillernder, sich an seinen eigenen Widersprüchen abarbeitender Text, der trotz aller Untersuchungen der letzten Jahrzehnte noch immer im Bewusstsein der Aufklärungsforschung viel zu wenig präsent ist. Dabei kann man nicht einmal sagen, dies

59 Raynal, Guillaume-Thomas: Histoire philosophique et politique, Bd. 5, S. $54 \mathrm{f}$. 
liege daran, dass diese französische Kolonialenzyklopädie nur eher marginal wahrgenommen worden wäre. Denn tatsächlich zählte das umfangreiche Werk trotz seiner Komplexität zu den großen Bestsellern der Lumières und wurde in zahlreiche europäische Sprachen übersetzt.

Es gehört sicherlich zu den charakteristischen Widersprüchen in diesem aus unterschiedlichen Texten unterschiedlicher Autoren zusammengesetzten und von Raynal in einem textuellen Brennspiegel vereinigten Bestseller der Aufklärung, dass sich die Reflexion der aktuellen Entwicklungen aus europäischer Perspektive auch auf die Möglichkeiten europäischer Machterhaltung im globalen Kontext bezog. In dieser weltpolitischen Frage aber ist die Position der Histoire des deux Indes unverkennbar an der Einsicht ausgerichtet, dass die geostrategische Bedeutung der Karibik nur dann in Zukunft noch für die einzelnen europäischen Nationen nutzbar sein dürfte, wenn ein weiterer Ausbau der jeweiligen Seestreitkräfte vorangetrieben werden kann. So heißt es im Schlussteil des vierzehnten Buches über diese fundamentalen geostrategischen Interessenlagen der europäischen Mächte:

Es gibt kein anderes Mittel, um die Inseln zu behalten, als eine Furcht einflößende Marine. In den Werften \& in den Häfen Europas müssen die Bastionen und Boulevards der Kolonien Amerikas gebaut werden. Während die Metropole sie gleichsam unter den Flügeln ihrer Schiffe haben wird; solange sie mit ihren Flotten das weite Intervall ausfüllt, das sie von ihren Inseln, den Töchtern ihres Gewerbfleißes \& ihrer Macht trennt; so lange wird ihre mütterliche Wachsamkeit über ihren Wohlstand für ihre anhaltende Anbindung verantwortlich sein. Folglich sind es die Seestreitkräfte, auf welche die Eigentümer der Neuen Welt von nun an ihr Augenmerk richten werden. Die Politik Europas will im Allgemeinen die Grenzen der Staaten mit Hilfe befestigter Plätze beibehalten. Doch für die Seemächte müsste es vielleicht Zitadellen in den Zentren \& Schiffe auf den Umwallungen geben. Eine Handel treibende Insel hat selbst keinen Bedarf an befestigten Plätzen. Ihre Verteidigungslinie ist das Meer, das ihre Sicherheit, ihre Subsistenz, ihren Reichtum garantiert. Die Winde stehen ihr zu Befehl, \& alle Elemente tragen zu ihrem Ruhme bei. ${ }^{60}$

Dieser geostrategische Entwurf, der auf die Förderung und den Ausbau der Seestreitkräfte setzt, entwirft in dieser Passage nicht nur die „Bastionen und Boulevards der Kolonien Amerikas“ in den Räumen zwischen den Inseln der Karibik. Er imaginiert zudem einen von den Mutterländern konzipierten und kontrollierten Bewegungs-Raum, der allein den Zielen der jeweiligen europäischen Macht dient und gerade auch der Piraterie und Freibeuterei ein Ende bereiten muss. Das Meer stellt in dieser Vision die Vielverbundenheit der Inseln sicher, bildet zugleich aber auch ihren Schutzwall vor feindlichen Angriffen jedweder Art. Das Meer ist insoweit das bewegende und verbindende Element schlechthin, zugleich aber auch

60 Ebda., Bd. 7, S. 118. 
das Medium einer Flotte, welche das „attachement“ der jeweiligen Insel und damit die Herrschaft Europas sicherstellt. Denn außereuropäische Kolonien kann in Europa nur beanspruchen, wer über Furcht einflößende Flotten verfügt.

Es geht um Insel-Welten und um Inselwelten in Übersee. Die Inseln erscheinen gleichzeitig als Inselwelt, mithin als ein weltweit vernetzter, aber in seinen Verbindungen von Europa dominierter Archipel unterschiedlichster Inseln, und als Insel-Welt, als je eigene, vom Meer geschützte Welt voneinander getrennter Inseln, die ihre je eigene Logik besitzen. ${ }^{61}$ So gibt die hier angeführte Passage des vierzehnten Buches eine klare Antwort auf die dem Schlusskapitel vorangestellte Frage „Quel doit être le sort futur des isles de l’Amérique“: Was also wird das künftige Schicksal der Inseln Amerikas sein? Die Antwort von GuillaumeThomas Raynal ist eindeutig: Nur wem es gelingt, die Welt der Karibik zugleich als Boulevard und als Bastion zu nutzen und damit gleichzeitig als Inselwelt und als Insel-Welt zu verstehen, wird es auch gelingen, den karibischen und zirkumkaribischen Raum nicht nur zu begreifen, sondern - wenn nötig - auch zu beherrschen.

Schauen wir nun ein klein wenig über das Ende des 18. Jahrhunderts hinaus in diese von Raynal apostrophierte Zukunft der transatlantischen wie der weltweiten Beziehungen! In einer dem zwischen April 1808 und Juli 1811 erstmals erschienenen Essai politique sur le royaume de la Nouvelle-Espagne beigegebenen Weltkarte hat Alexander von Humboldt eine höchst interessante Bewegungskarte weltweiter Verschiffungen von Edelmetallen vorgelegt. Seine „Carte des diverses Routes par lesquelles les richesses métalliques refluent d'un Continent à l'autre“, also eine Karte der verschiedenen Wege, auf denen die reichen Bodenschätze von einem Kontinent zum anderen gelangen (Abb. 5). Diese kunstvolle Karte ist mit einigen überraschenden und auch hintersinnigen Details ausgestaltet. So hat Humboldt hier dem kleinen Städtchen Freiberg in Sachsen, wo er an der berühmten Bergakademie studiert hatte, durch die Einzeichnung in eine ansonsten weitgehend städteleere Kartierung Europas ein kleines ironisches Denkmal errichtet. Anders als Juan de la Cosa oder Guillaume-Thomas Raynal wählte er jedoch den Ausschnitt so, dass Europa nicht im Zentrum, sondern am jeweils östlichen und westlichen Kartenrand eingezeichnet wurde. Nur eine kartographische Grille dieses im vollen Wortsinne europäischen Reisenden, der sich strikt gegen jede Art von Kolonialismus wandte?

Auffällig ist, dass Humboldt dabei nicht nur die verschiedenen Routen, sondern in herausgehobener Form auch viele Inseln und Archipele einzeichnete, welche sich - und dies ist kein Zufall - häufig entlang der eingetragenen

61 Zur Unterscheidung zwischen Inselwelt und Insel-Welt vgl. Ette, Ottmar: Von Inseln, Grenzen und Vektoren. Versuch über die fraktale Inselwelt der Karibik. In: Braig, Marianne / Ette, Ottmar / Ingenschay, Dieter / Maihold, Günther (Hg.): Grenzen der Macht - Macht der Grenzen. Lateinamerika im globalen Kontext. Frankfurt am Main: Vervuert Verlag 2005, S. 135-180. 


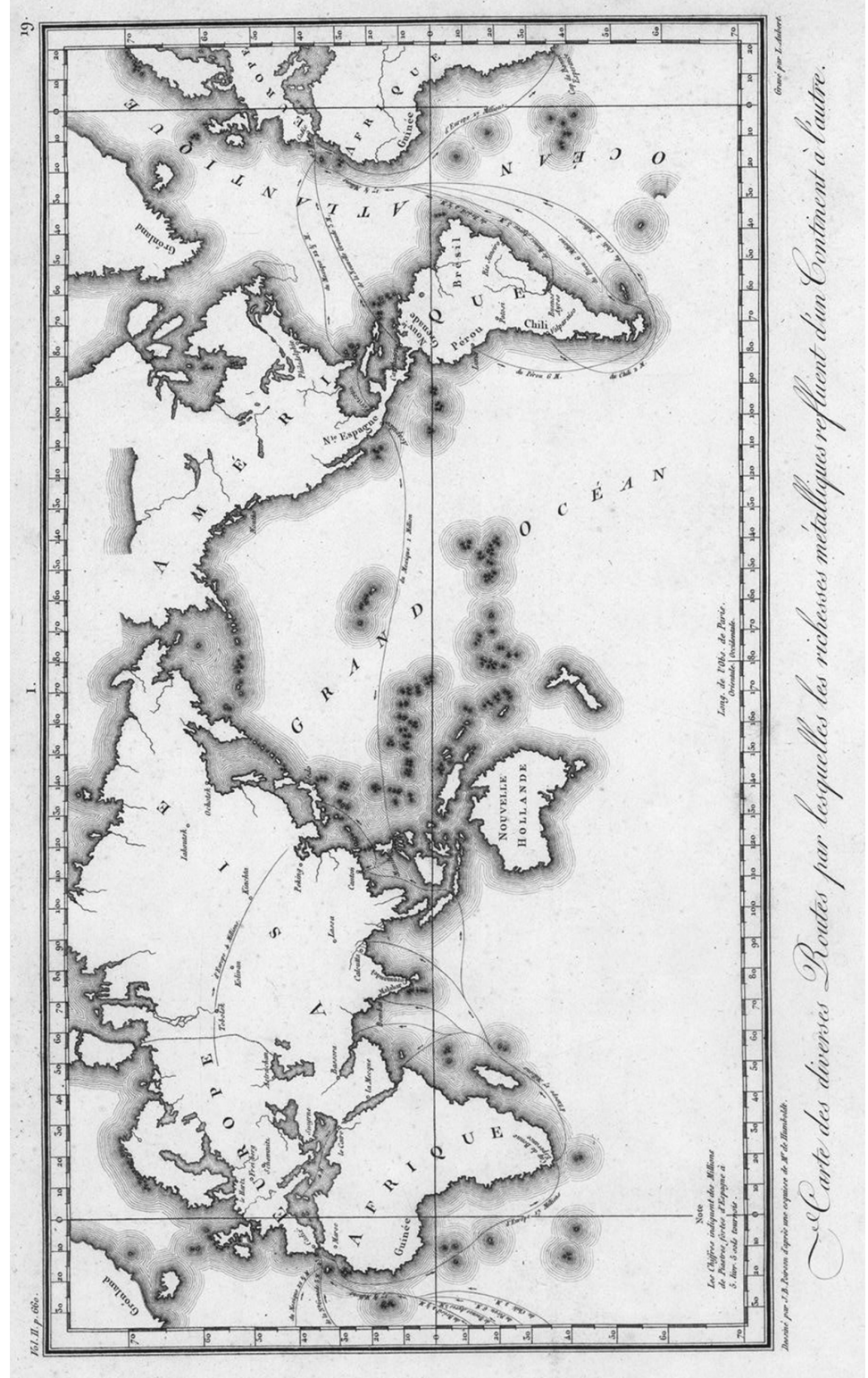

Abb. 5: Alexander von Humboldt: Carte des diverses routes par lesquelles les richesses métalliques refluent d'un continent à l'autre, aus dem Essai politique sur le royaume de la Nouvelle-Espagne, 1808-1811. 
Transportwege situieren. Der Versuch, von einer raumgeschichtlichen zu einer bewegungsgeschichtlichen Sichtweise zu gelangen, verknüpft sich bei Alexander von Humboldt stets mit einem ausgeprägten Interesse an Inseln und Inselwelten: In ihnen erkannte er ein immer wieder dynamisierendes, die Zirkulation des Wissens wie der Waren akzelerierendes Element. So lässt sich seine Karte unschwer als eine Bewegungskarte auffassen, welche deutlich das bewegungsgeschichtliche Verständnis weltumspannender Verbindungen im Denken des Natur- und Kulturforschers anzeigt.

Bei einer genaueren Betrachtung der Humboldt'schen Wegekarte zeigt sich nicht nur, dass die Karibik über zwei Routen zwischen der Alten Welt und Neuspanien sowie Neugranada verbunden ist, sondern zugleich auch über das neuspanische Festland und den Hafen von Acapulco mit den Philippinen und dem Hafen von Kanton auf dem asiatischen Festland korrespondiert. Dies unterstreicht die herausgehobene Stellung des karibischen Raumes innerhalb des gesamten Weltverkehrs und die Tatsache, dass die Karibik früh schon zu den am dichtesten globalisierten Areas dieses Planeten zählte. Doch gerade die an Umfang geringere Route über Neuspanien und die Philippinen war kulturgeschichtlich wie transkulturell von großer Bedeutung. Anders als im Falle des Atlantik, der auf Humboldts Karte von unterschiedlichsten Routen gequert wird, handelt es sich dabei um den einzigen Transportweg, der den weiten transpazifischen Raum durchläuft, welcher ins Zentrum des Kartenblattes gerückt ist.

Vergessen wir vor dem Hintergrund dieser Bewegungs-Karte nicht, dass Serge Gruzinski in seiner Studie über die Globalisierung im 16. Jahrhundert ${ }^{62}$ die Tatsache in Erinnerung rief, dass Spanien mit der Eroberung der Philippinen die Schaffung eines wahrhaft weltumspannenden Reiches abschloss. Dessen einzelne Teile waren nicht nur prioritär an Spanien zurückgebunden, sondern vernetzten sich auch im Rahmen der von der Kolonialmacht gegebenen und überwachten Möglichkeiten intern. Die Inselwelten der Philippinen nahmen in diesem Zusammenhang eine gegenüber den Antillen analoge Stellung ein. Zugleich wuchs insbesondere Neu-Spanien noch im 16. Jahrhundert in eine geostrategisch wie ökonomisch bedeutsame Rolle, insofern von der Hauptstadt des Vizekönigreiches aus über die Häfen Veracruz und Acapulco die transatlantischen mit den transpazifischen Verbindungswegen verknüpft werden konnten. Schon 1566 wurde im Rahmen der Expedition von Miguel de Legazpi eine Route gefunden, die von den Philippinen nach Neu-Spanien zurückführte, so dass ab diesem Zeitpunkt keine Verschiffung von Menschen oder Waren über asiatische Häfen mehr

62 Vgl. Gruzinski, Serge: Les Quatre Parties du monde. Histoire d'une mondialisation. Paris: Editions de La Martinière 2006, u. a. S. 131. 
notwendig war, sondern - wie Gruzinski formulierte - Asien in Amerika ankam. ${ }^{63}$ Das von Europa aus gezogene Netz um die Erde war geschlossen - wenn auch noch weitmaschig. Im Folgenden ging es darum, es für die iberischen Kolonialmächte noch effizienter zu gestalten.

Mit diesen globalgeschichtlich bedeutungsvollen Tatsachen und Ereignissen waren weniger als ein halbes Jahrhundert nach der ersten Weltumsegelung Magellans beziehungsweise Elcanos im Auftrag Spaniens die nautischen und infrastrukturellen Grundlagen für eine den gesamten Erdball umspannende Wirtschaft mit ihren ebenso von festen wie schwimmenden Bastionen zu schützenden Transportrouten gelegt. Europa sollte dieses Netzwerk bis zur „Independencia“ der iberischen Kolonien, die sich am Ausgang des 18. Jahrhunderts - und Humboldts Reiseberichte liefern hierfür den Beleg - bereits abzeichnete, nicht mehr aus den Händen lassen. Diese asymmetrische ,Symbiose‘ liegt auch dem 18. Jahrhundert zu Grunde; und zwar nicht allein der „Géographie des Lumières“, sondern der Wirtschafts- und Sozialstruktur der europäischen Mutterländer und der mit ihnen binneneuropäisch verflochtenen Staaten. Zugleich war die karibische Inselwelt damit zu einem überaus wichtigen Teil eines Systems von Häfen und Handelsplätzen, von Werften und Waffenschmieden, von Forts und Finanztransfers geworden, in dessen weiterer Entwicklung die Karibik einschließlich eines Teiles ihrer Festlandsäume mit der zusätzlichen Intensivierung der auf der Arbeit afrikanischer Sklaven beruhenden Plantagenwirtschaft zu einem Raum verdichtetster Globalisierung avancierte. Die Karibik war ohne Europa nicht zu denken - und darüber vergisst man aus europäischer Sicht leicht, dass auch das Umgekehrte galt.

Alexander von Humboldt, der wohl erste Globalisierungstheoretiker, hat sich mit dieser frühen Schlüsselstelle des Welthandels und des Transports von Rohstoffen wie Fertigprodukten über lange Jahrzehnte sehr intensiv beschäftigt. Konsequenterweise hat er in seinen verschiedenen Kartenwerken nicht nur ein Profil Neu-Spaniens zwischen den Häfen Acapulco und Veracruz erstellt und unterschiedliche, auch kartographisch festgehaltene Varianten für den Bau eines interozeanischen Kanals vorgeschlagen, der über den karibischen Raum die transatlantischen mit den transpazifischen Routen noch effizienter verbinden sollte. Auch die exakte kartographische Aufnahme des karibischen und zirkumkaribischen Raumes gehört zweifellos zu den großen Leistungen des Preußen, die keineswegs nur das kartographische Bild von der neuen Welt grundlegend veränderten. Er fasste zu Beginn des 19. Jahrhunderts die Ergebnisse des 18. Jahrhunderts zusammen und hob sie am Ausgang des Siècle des Lumières

63 Ebda. 
auf eine neue Stufe. Diesbezüglich sprach er selbst von einer weltweit erfolgenden „glücklichen Revolution“. 64

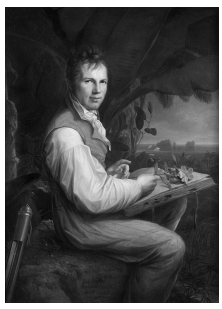

Abb. 6: Friedrich Georg Weitsch: Alexander von Humboldt (1769-1859).

Vergleicht man die beiden Humboldt'schen Kuba-Karten des Atlas géographique et physique mit kartographischen Darstellungen, wie sie etwa Guillaume-Thomas Raynals Histoire philosophique et politique des établissemens et du commerce des Européens dans les deux Indes noch beigegeben wurden, so wird mit Blick auf die Darstellungsweise, die Präzision ihrer astronomischen Messungen und Ortsangaben sowie die Detailtreue ihrer kartographischen Visualisierung deutlich. Ein gewaltiger Sprung wird augenfällig, der die Humboldt'schen Kartenwerke auszeichnet. Sie beruhten auf unermüdlich während seiner Reise durch die amerikanischen Tropen unternommenen Beobachtungen, aber auch auf vielen anderen Messungen und gewiss auch den Ergebnissen des Jahrhunderts der Aufklärung. Das moderne Bild von der Erde, von unserer Welt, war entstanden.

Die gesamte Karibik war für Alexander von Humboldt ein vielgestaltiger Transitraum, in dem sich nicht nur mit Blick auf die Haitianische Revolution weltweit relevante Entwicklungen anbahnten. Auf diese Fragestellungen werden wir in unserer Vorlesung noch ausführlich eingehen. Humboldts Kartographie und die mit ihm verbundenen Kartographen waren an weltweiten Bewegungen ausgerichtet. Lässt sich aber auch ein enger gewählter Ausschnitt kartographisch als Bewegungs-Raum skizzieren? Die beiden Karten der Insel Kuba, die Alexander von Humboldt dem Kartenwerk des Atlas géographique et physique des régions équinoxiales du Nouveau Continent in seinem amerikanischen Reisewerk beigab, präsentieren uns den rechteckigen Ausschnitt einer Insel, die als separate Darstellung gleichsam aus dem Zusammenhang der karibischen Inseln und Festlandsäume herausgeschnitten ist. Sie ordnen sich dem erstmals 1826 separat in zwei Bänden

64 Vgl. hierzu Ette, Ottmar: „Para edificar el templo de la libertad.“ París - Berlín - Haití - México: Alexander von Humboldt, de revolución en revolución. In: Leyva, Gustavo / Connaughton, Brian / Díaz, Rodrigo / García Canclini, Néstor / Illades, Carlos (Hg.): Independencia y Revolución. Pasado, Presente y Futuro. México: Fondo de Cultura Económica - Universidad Autónoma Metropolitana 2010, S. 591-619. 
zu Paris erschienenen Essai politique sur l'île de $C u b a^{65} \mathrm{zu}$, der ursprünglich im Kontext von Humboldts Relation historique, dem eigentlichen Reisebericht von seiner Forschungsexpedition mit Aimé Bonpland durch die Amerikas, im dritten Band entstanden war. Diese ikonotextuelle, Text und (Karten-) Bild miteinander verbindende Relation gilt es einen Augenblick lang genauer im Auge zu behalten.

Die auffällige generische Titelgleichheit des Politischen Versuchs über die Insel Cuba mit Humboldts Jahre zuvor erschienenen Essai politique sur le royaume de la Nouvelle-Espagne darf jenseits wissenschaftlicher, epistemologischer wie literarischer Gründe durchaus auf eine Intentionalität der Benennung zurückgeführt werden. Der preußische Gelehrte wusste sehr wohl, dass sein erster Essai politique von vielen gerade auch amerikanischen Lesern wie eine Art Geburtsurkunde eines unabhängigen Mexiko gelesen wurde und dem emergierenden Nationalstaat förmlich in die Wiege gelegt worden war. Was also gab Alexander von Humboldt der größten der Antilleninseln mit auf den Weg? Dachte er bereits an den künftigen Nationalstaat Kuba?

Als anderthalb Jahrzehnte nach dem bisweilen fälschlich als „Mexiko-Werk“ bezeichneten Essai Humboldts Versuch über Kuba in den Druck ging, war die Entstehung des jungen Staates Mexiko zwar noch immer mit vielen Turbulenzen verbunden, aber ein historisches Faktum, das Humboldt, dessen amerikanisches Reisewerk die Unabhängigkeitsrevolution in den spanischen Kolonien über die entscheidenden Jahrzehnte begleitete, überaus bewusst sein musste. Dass er seinem Essai politique sur l'île de Cuba kartographische Darstellungen beigab, die eine spanische Kolonie gleichsam losgelöst von ihren geographischen und topographischen Kontexten in einem separaten Kartenbild präsentierten, darf folglich sehr wohl als ein belastbares Indiz gewertet werden. Es handelt sich um den Hinweis darauf, dass Humboldt die für den europäischen Handel immer wichtiger werdende Insel als protonationale Einheit verstand - und auch verstanden wissen wollte. Humboldt war sich seiner Titelgebung und der Auskoppelung des nun separierten Werkes aus seinem amerikanischen Reisebericht sehr wohl bewusst.

Zwischen den Karten von 1820 und 1826 (Abb. 7a u. 7b) gibt es leicht erkennbare Veränderungen im Verlauf der dargestellten Gebirge, Verbesserungen fehlerhafter Einträge oder leichte Korrekturen der astronomischen Berechnungen, die Humboldt dank zusätzlicher Hinweise sowie fremder Messungen und Berichtigungen einarbeiten konnte. Sie lassen ein Bild der Insel Kuba mit zahlreichen sie umgebenden kleineren und größeren Inseln - einschließlich der Isla de Pinos

65 Humboldt, Alexander von: Essai politique sur l'île de Cuba. Avec une carte et un supplément qui renferme des considérations sur la population, la richesse territoriale et le commerce de l'Archipel des Antilles et de Colombia. 2 Bde. Paris: Librairie de Gide fils 1826. 


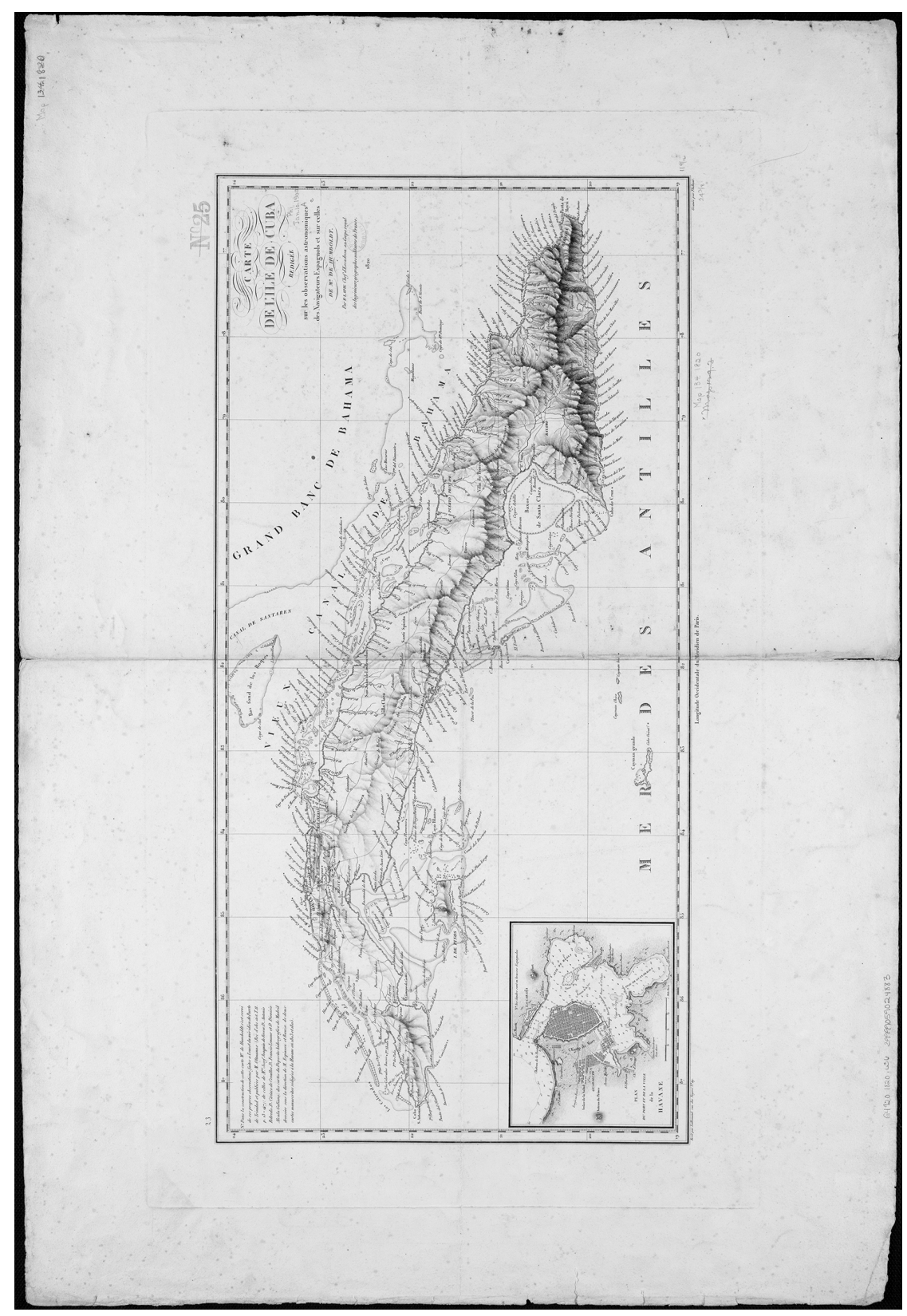

Abb. 7a: Alexander von Humboldt: Karte der Insel Kuba, mit einer Nebenkarte „Plan des Hafens der Stadt Havanna“, aus dem Atlas géographique et physique des régions équinoxiales du Nouveau Continent (1814-1838), 1820. 


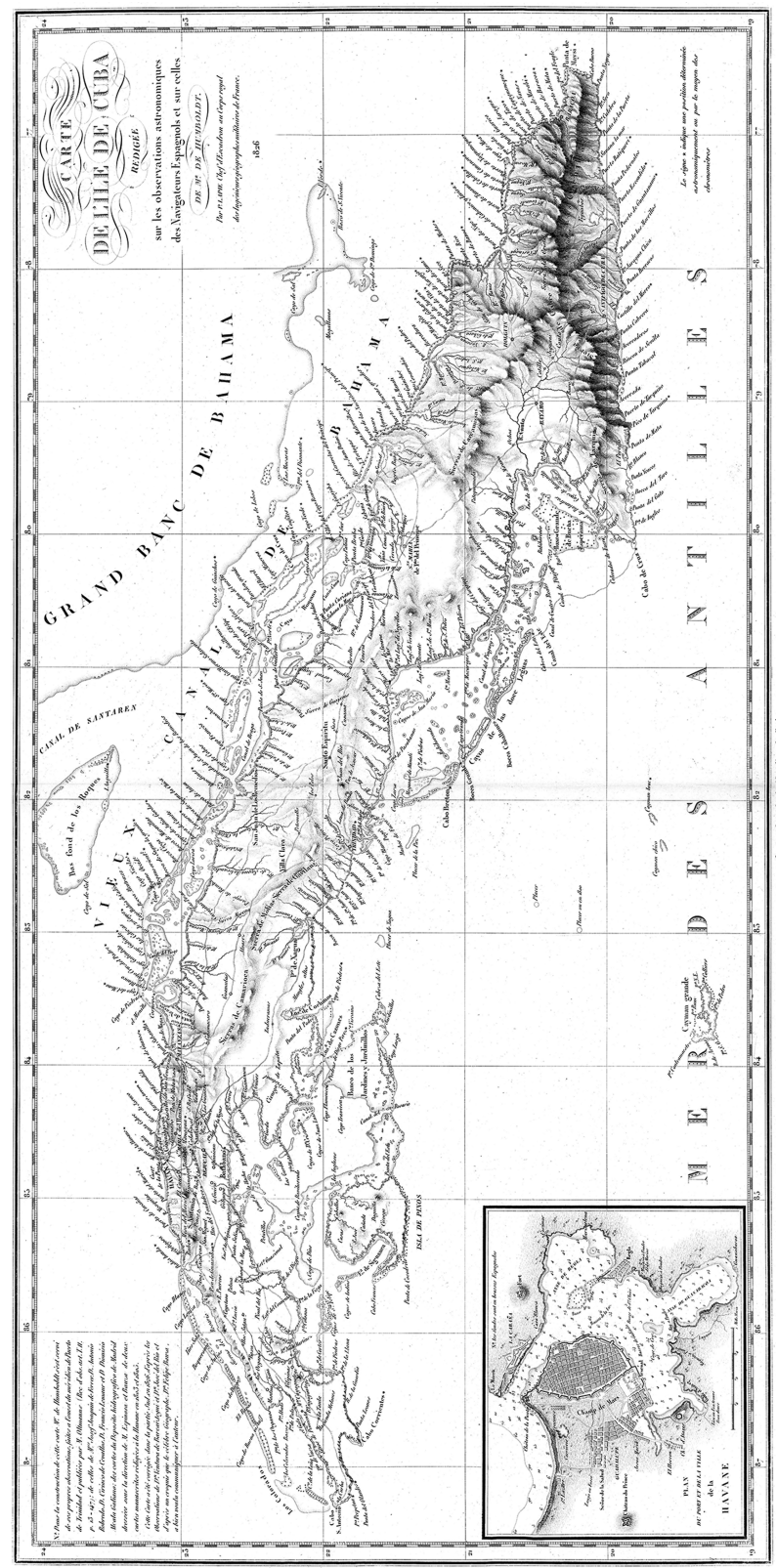

Abb. 7b: Alexander von Humboldt: Karte der Insel Kuba, mit einer Nebenkarte „Plan des Hafens der Stadt Havanna“, aus dem Atlas géographique et physique des régions équinoxiales du Nouveau Continent (1814-1838), 1826. 
- entstehen, das aktuellen Kartendarstellungen überaus nahe kommt. Man darf daher ohne jede Übertreibung sagen, dass so das Kartenbild des modernen Kuba als unabhängiger Inselstaat geschaffen wurde.

Dabei gelang es Alexander von Humboldt, der gemeinsam mit seinem Freund de Walckenaer die Karte des Juan de la Cosa wiederentdeckt hatte, die Statik einer abgetrennten, separaten Darstellung der Insel durch den in die Karten von 1820 wie von 1826 aufgenommenen detailreichen Plan des Hafens von Havanna zugunsten einer dynamischen Sichtweise zu überwinden. Er integrierte sie in die seit dem Jahres 1500 belegbare Visualisierung einer planetarischen Bewegungsgeschichte. Denn war es nicht dieser Hafen, der einst die gesamte spanische Flotte aufzunehmen vermochte, der Kuba als Teil einer von Europa dominierten Bewegungsgeschichte seit der ersten Phase beschleunigter Globalisierung als globale Insel entstehen ließ?

Es ist mithin von größter Bedeutung, dass Alexander von Humboldt gleich an den Anfang seiner umfangreichen Ausführungen über Kuba ein wohldurchdachtes literarisches Portrait des berühmten Hafens von Havanna stellte. Und so überrascht es auch nicht, dass der kubanische Schriftsteller Alejo Carpentier diese Passage eines von einem Preußen in französischer Sprache verfassten kubanischen Gründungstextes seinerseits als beziehungsreiches Incipit seines schönen Bandes La Ciudad de las Columnas ${ }^{66}$ über Havanna, Die Stadt der Säulen, verwendete. Dabei mag es bedeutungsvoll erscheinen, dass der preußische Reisende und Schriftsteller die kubanische Hauptstadt just im ersten Jahr eines neuen Jahrhunderts erreichte.

Denn Humboldt schilderte im 28. Kapitel seiner Relation historique, deren itinerarische Struktur nach dieser wichtigen Passage in eine vorwiegend deskriptive und diskursive Dimension überführt wird, auf spektakuläre Weise aus der Bewegung, einem literarischen Travelling heraus ${ }^{67}$ jenen Bewegungs-Raum des Hafens. Diesen lernte er zum ersten Mal an jenem 19. Dezember des Jahres 1800 kennen und an ihm kreuzen sich die verschiedenartigsten Wege, die unterschiedlichsten Bewegungen:

Bei der Einfahrt in den Hafen ist der Anblick von Havanna einer der strahlendsten und malerischsten unter all jenen, die man an den Gestaden des äquinoktialen Amerika nördlich des Äquators genießen kann. Dieser von den Reisenden aller Nationen gefeierte Ort

66 Carpentier, Alejo: La Ciudad de las Columnas. Havanna: Editorial Letras Cubanas 1982, S. 7-10.

67 Vgl. hierzu Ette, Ottmar: Eine „Gemütsverfassung moralischer Unruhe“ - „Humboldtian Writing“: Alexander von Humboldt und das Schreiben in der Moderne. In: Ette, Ottmar / Hermanns, Ute / Scherer, Bernd M. / Suckow, Christian (Hg.): Alexander von Humboldt - Aufbruch in die Moderne. Berlin: Akademie Verlag 2001, S. 33-55. 
besitzt weder die Überfülle an Vegetation, welche die Ufer des Flusses von Guayaquil schmückt, noch die wilde Majestät der felsigen Küste von Rio de Janeiro, zwei Häfen der südlichen Hemisphäre: Doch die Anmut, die in unseren Klimaten die Szenerie einer in Kultur genommenen Natur verschönert, mischt sich hier mit der Majestät der Pflanzenformen, mit der organischen Kraft, welche die torride Zone charakterisiert. In einer Mischung von so süßen Eindrücken vergißt der Europäer die Gefahr, die ihn im Schoße der volkreichen Städte der Antillen bedroht; er sucht, die verschiedenartigen Elemente einer weiten Landschaft zu ergreifen, diese Befestigungen zu betrachten, welche die Felsen im Osten des Hafens krönen, dieses innere Becken, das von Dörfern und Höfen gesäumt ist, diese Palmen, die sich in schwindelnde Höhe erheben, diese Stadt, die halb von einem Wald an Schiffsmasten und den Segeln der Schiffe verborgen wird. ${ }^{68}$

Wie in einer literarischen Mise en abyme und ganz jener fraktalen Schreibweise treu, mit deren Hilfe Humboldt immer wieder die überraschendsten Wechselwirkungen und Beziehungsgeflechte zu einer fundamental-komplexen erzähltechnischen Struktur verdichtet, ${ }^{69}$ wird der kartographisch-dargestellte Hafen von Havanna hier ästhetisch in Bewegung gesetzt und als Teil einer globalen Bewegungsgeschichte inszeniert. Die ikonotextuelle Verbindung zur kartographischen Hafendarstellung ist dabei evident. Der Hafen von Havanna sowie die gesamte Insel Kuba werden nicht als ein statischer, territorialer Raum, sondern als mobiler Bewegungsraum innerhalb eines weltumspannenden infrastrukturellen Gefüges perspektiviert.

Denn die gleichsam hemisphärische Kontrastierung mit anderen Häfen der Neuen Welt leitet über zu einer Deutung von Hafen und Stadt als dynamischem Zwischenraum, der Bewegungen in nord-südlicher wie west-östlicher Richtung in sich aufnimmt und übersetzt. Dabei soll uns an dieser Stelle nicht kümmern, dass Humboldt wohl den Hafen von Guayaquil, nicht aber jenen von Rio de Janeiro aus eigener Anschauung kannte. Im Hafen von La Habana überkreuzen sich die klimatischen Bedingungen der gemäßigten Zone und die „kultivierte Natur“ des Nordens einerseits mit der „Majestät“ tropischer Gewächse, wie sie die heiße Zone charakterisieren: Havanna, die Stadt der Säulen Carpentiers, besaß als hochgradig vektorisierter Kreuzungspunkt von Beginn des ersten Kontakts, der Einfahrt in den Hafen, eine enorme Anziehungskraft auf den preußischen Weltreisenden.

68 Humboldt, Alexander von: Relation historique du Voyage aux Régions équinoxiales du Nouveau Continent ... Nachdruck des 1814-1825 in Paris erschienenen vollständigen Originals, besorgt, eingeleitet und um ein Register vermehrt von Hanno Beck. Bd. III. Stuttgart: Brockhaus 1970, S. 348.

69 Zur Bedeutung des Fraktalen für die Literaturen der Welt vgl. Ette, Ottmar: WeltFraktale. Wege durch die Literaturen der Welt. Stuttgart: J.B. Metzler Verlag 2017. 
So erscheint der Hafen von Havanna von Anfang an als Ort einer Zirkulation, die offenkundig - innerhalb einer hemisphärischen Konstruktion - den Norden mit dem Süden und zugleich - innerhalb eines transatlantischen Übersetzens - Amerika mit Europa, aber auch mit Afrika verbindet. Wir könnten an dieser Stelle sagen, dass genau dies der Raum jenes Jahrhunderts der Aufklärung, jenes Siècle des Lumières ist, welche unsere Vorlesung über die Aufklärung zwischen zwei Welten beleuchten will. Die Insel Kuba wird - dies machen diese faszinierend gestaltete Passage, aber auch viele andere Stellen deutlich nicht von ihrer Territorialität, ihrer statischen Oberfläche her gedacht, sondern aus ihren historisch akkumulierten Dynamiken konstruiert. Der Raum entsteht erst durch die Bewegungen, die ihn auf den verschiedensten Ebenen queren und kreuzen - eine transareale Konstruktionsweise, derer sich Humboldt mit großem literarischen Geschick bedient. Aus eben diesem Grunde ist das eingesetzte literarische Travelling der mobilen Beobachterperspektive das ästhetisch adäquate Schreibverfahren, das es überdies erlaubt, autobiographische Modi des 18. Jahrhunderts in den raffiniert gestalteten Reisetext einzublenden.

Nicht zu Unrecht sprach Alejo Carpentier mit Blick auf Havanna „de lo abigarrado, de lo entremezclado, de lo encajado entre realidades distintas“: ${ }^{70}$ Havanna verweist mit seinem Aufeinandertreffen verschiedenster Realitäten und mit der zutiefst heterogenen Strukturierung seiner gesamten Anlage immer auch auf ein Anderswo. Es deutet auf eine nirgendwo endende Relationalität - oder mit den Worten Carpentiers, welche die Begrifflichkeiten von Fernando Ortiz barockisieren, auf das „Mestizische all dessen, was sich auf diesen Inseln des amerikanischen Mittelmeeres transkulturierte“, auf das „mestizo de cuanto se transculturizó en estas islas del Mediterráneo americano“. ${ }^{71}$ Auf eindrucksvolle Weise präsentiert sich die gesamte Karibik als transkulturiertes und transkulturierendes Meer der amerikanischen Mitte.

Auch bei Alexander von Humboldt steht die Welt der Tropen topisch für die Fülle, doch kann sich diese - dem abendländischen Tropenbild gemäß rasch in eine Falle verwandeln, wie die obige Passage ebenfalls andeutet. Denn der unbedarfte Reisende ahnt nichts von den Gefahren, welche hier auf ihn lauern. Die Gegensätze von Natur und Kultur, von Stadt und Land, von mobilem Wasser und festem Fels werden sorgfältig miteinander verwoben und vermischt, so dass sich eine bewegte und zugleich bewegende Szenerie entfaltet, welche die Tropeninsel Kuba vom Hafen von Havanna aus nicht-statisch perspektiviert. Denn Kuba ist - und darum tat Carpentier gut daran, seinen Text mit Humboldt

70 Carpentier, Alejo: La Ciudad de las Columnas, S. 14.

71 Ebda., S. 84. 
beginnen zu lassen - nur aus bewegungsgeschichtlicher Perspektive zu begreifen. In dieser Stadt schlägt das Herz der Antillen und Amerikas ebenso wie die Herzen Europas, Afrikas und Asiens.

Mit dem Hafen als fraktalem Muster setzt Humboldt die Insel folgerichtig als wichtigen Teil einer globalen Bewegungsgeschichte in Szene, innerhalb derer höchst gegensätzliche Klimate, Pflanzenformen, Städte und Bevölkerungen miteinander in Austausch treten. Kuba wird unter der Feder Humboldt zu einem WeltFraktal. Im Kontext der Migrationen unterschiedlichster (pflanzlicher, tierischer oder menschlicher) Lebewesen setzt eine Zirkulation von Wissen, Waren und Menschen ein - und auch von Menschen als Waren. Denn früh schon wird der Blick des Lesepublikums auf den Verkauf der unglücklichen Sklaven gelenkt, der „malheureux esclaves“. ${ }^{72}$ Das Zirkulieren umfasst Kulturen und Sprachen, Traditionen und Ideen, die erst entstehen ließen, was in der Folge untersucht werden kann: unter der Insel andere Inseln, unter dem Archipel andere Archipele. Kuba ist die Insel der Inseln. ${ }^{73}$

Wie wäre Kuba, das eine gewichtige Rolle ebenso in der ersten wie der zweiten, aber später auch - im letzten Drittel des 19. Jahrhunderts - in der dritten Phase beschleunigter Globalisierung spielte, besser zu porträtieren denn als Insel im transozeanischen Bewegungsraum? Der tropischen Fülle der Palmen an Land entsprechen ganze Wälder von Masten, die mit ihren Segeln die Fülle der vom Menschen initiierten Zirkulationsformen repräsentieren. Die Welt ist nicht nur zum Archipel gekommen, sie ist zum Archipel geworden. In La Habana zeigt sich das 18. Jahrhundert zwischen zwei Welten dank der Sklaverei von seiner brutalsten und menschenverachtendsten, aber auch dank seiner kreativen Überlappungen in seiner schillerndsten und vielleicht faszinierendsten Art und Weise. Wir werden dieser Doppelgestaltigkeit des Jahrhunderts der Aufklärung, ja dieser um mit Horkheimer und Adorno zu sprechen - Dialektik der Aufklärung ${ }^{74}$ in aller wünschenswerten Ausführlichkeit nachgehen. Gerade im karibischen Raum, in den Kolonien Europas, wird sie besonders anschaulich.

Die Sklaverei in den Städten wie auf den Plantagen, gegen die sich Humboldt in seinem Essai politique ein ums andere Mal entschlossen aussprach, war für den Schriftsteller und Intellektuellen avant la lettre Teil dieser Realität und ein Produkt dieser weltweiten Austauschbeziehungen, mithin einer Globalisierung, deren Schattenseiten er immer wieder sehr präzise aufzeichnete. Ge-

72 Humboldt, Alexander von: Relation historique, Bd. III, S. 350.

73 Vgl. hierzu Ette, Ottmar: Kuba - Insel der Inseln. In: Ette, Ottmar / Franzbach, Martin (Hg.): Kuba heute. Politik, Wirtschaft, Kultur. Frankfurt am Main: Vervuert Verlag 2001, S. 9-25. 74 Vgl. Horkheimer, Max / Adorno, Theodor W.: Dialektik der Aufklärung. Philosophische Fragmente. Mit einem Nachwort von Jürgen Habermas. Frankfurt am Main: Fischer 1986. 
rade mit Blick auf die Haitianische Revolution, die zum Zeitpunkt seiner beiden Kuba-Aufenthalte in ihre finale Phase getreten war, wusste Alexander von Humboldt, wie entscheidend die Abschaffung der Sklaverei und die Anbahnung neuer Formen des Zusammenlebens zwischen verschiedenen Kulturen, Ethnien, Religionen und Sprachen für die Zukunft nicht allein auf dem amerikanischen Kontinent sein musste und sein würde.

Vor dem Hintergrund der revolutionären Ereignisse in Saint-Domingue, ${ }^{75}$ der ehemals reichsten europäischen Kolonie der Antillen, aber auch angesichts der Französischen Revolution und seines eigenen Erlebens des revolutionären Paris wusste Humboldt, wie rasch sich unter dem Einfluss erst einmal in Zirkulation gesetzter Ideen stets für stabil gehaltene Strukturen fast über Nacht und zukunftsoffen verändern konnten. Das 18. Jahrhundert ist ohne seine Dialektik, aber auch ohne seine Revolutionen nicht zu denken. Gerade die globalhistorisch so wichtige Haitianische Revolution war ein Kind jener Aufklärung zwischen zwei Welten, welche unsere Vorlesung präziser $\mathrm{zu}$ fassen sucht. Mit diesen Einsichten und Überlegungen mag diese Einführung in das Feld unserer Vorlesung zu Ende gehen: Der gesamte Bewegungs-Raum einer Aufklärung, die sich zwischen zwei Welten entfaltet, liegt nun vor uns und will aus verschiedensten Perspektiven bearbeitet und durchquert werden.

75 Vgl. die Kapitel zur Haitianischen Revolution zu Beginn der vierten „Aula“-Vorlesung in Ette, Ottmar: Romantik zwischen zwei Welten, S. 100-150 u. S. 191-250. 
